\title{
DEVELOPING THE TRADITIONAL METHODS FOR MODERNIZATION AND MAINTENANCE THE MUD BRICK HOUSE (THE CITY OF SHIBAM HADHRAMOUT AS A MODEL)
}

\section{Khaled Nasser Barashed and Sabet Salem EL-Azab}

Department of Architecture, Faculty of Engineering

(Received August 12, 2007 Accepted October 31, 2007)

Yemen in general and Hadhramout in particular is replete with a rich cultural, tradition and ancient heritage. The most important one is the clay architecture arts; in Hadhramout there are many of the examples of the clay architecture such as some existed cities full of life. The most famous and important one is the Historical City of Shibam with its wall. Shibam with its palaces, fortresses, towers and houses with over 500 years of age. Their altitude reaches up to eight floors. They are considered the oldest altitude skyscrapers in the world.

Despite that the city is inhabited but its buildings still need maintenance. Also the existence of its buildings in an old architecture environment makes them suffer from physical infrastructure limitations and their inability to meet the emerging needs of life and the prosperity of modern health services - such as health services, spacious rooms and other requirements of the Modern House in addition to ongoing maintenance requirements. This made them vulnerable to emigrate and serious neglect, and hence the deterioration and oblivion.

Despite their traditional expertise for hundreds of years in building operations and maintenance, but there were some errors and deficiencies in circulation across generations need to be correct and re-examined in order to access to scientific solutions in the industry of mud bricks, roofing, and the outside layer (the coating) as well as addressing the cracks and mud building diseases .

This research aims to study the buildings-maintenance of the historical city of Shibam Hadhramout, at this time as a model for ways to restore mud buildings with the traditional methods to come up with recommendations aimed to develop the maintenance and modernization of the house in a steady scientific method .

KEYWords: maintenance, repair, mud buildings, the city of Shibam Hadhramout, Yemen.

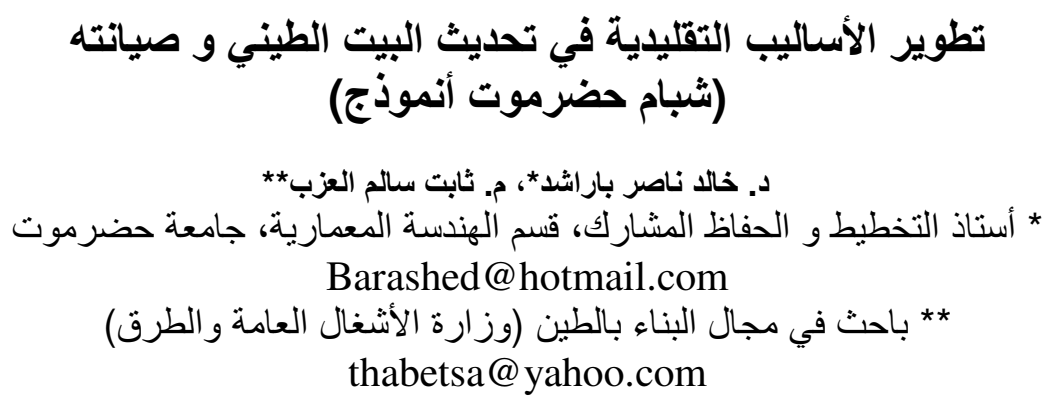

\footnotetext{
الملخص

تزخر اليمن بشكل عام وحضرموت على وجه الخصوص بموروث ثقافي وتر اثي و أثري أبرز هـا فنون

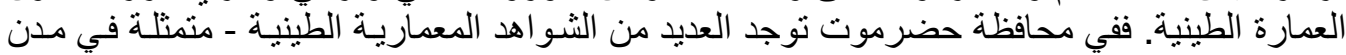

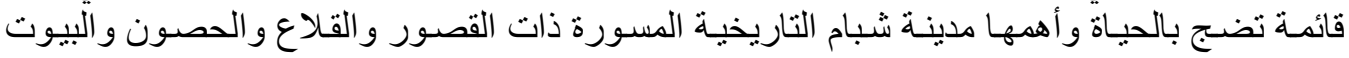


و التي يزيد عمر بعضها عن . .0 عام ويبلغ ارتفاع مبانيها إلى ثمانية طو ابق، حيث تعد أقدم ناطحات

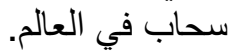

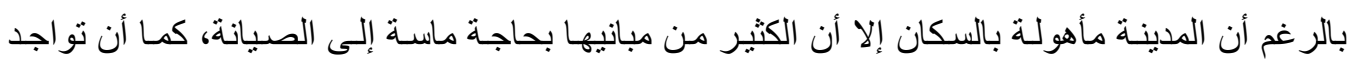

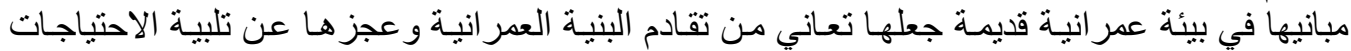

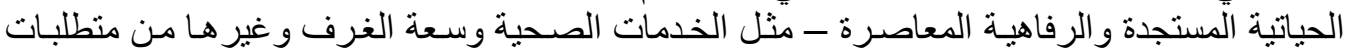

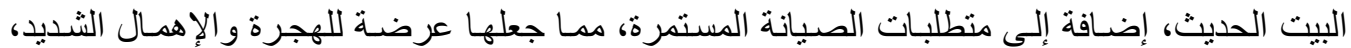

$$
\text { ومن ثم للتدهور و الاندثار. }
$$

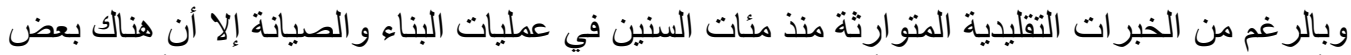

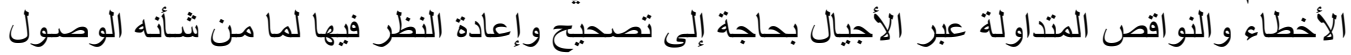

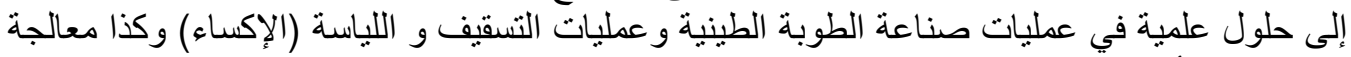
التشققات و الأمر اض التي تصيب العمارة الطينية.

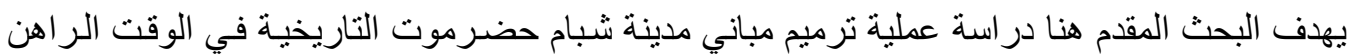

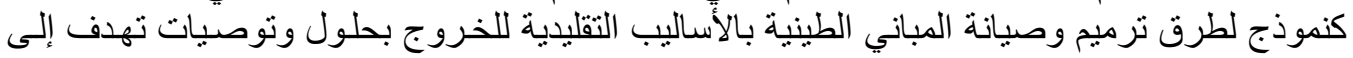
تطوير عملية الصيانة و التحديث للبيث الطيني بمنهاج علمي رصين.

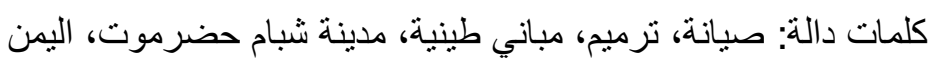

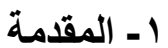

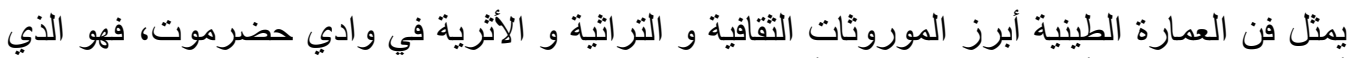

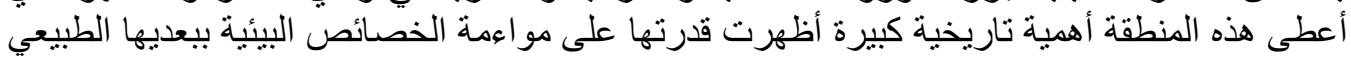

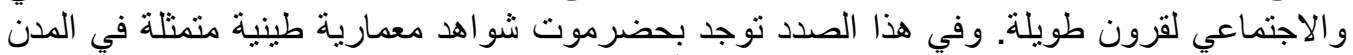

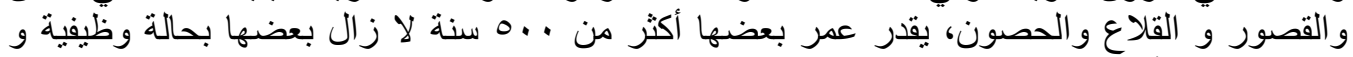

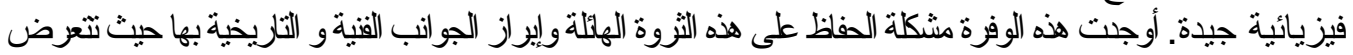
إلى الكثير من الإهمل و سوء الإستعمال. إلا أنه جدير بالإشارة ونتيجة لعوامل عدة الإنها لإنها الهجرة وزيادة ضغط الاحتياجات الوظيفية والمعيشية

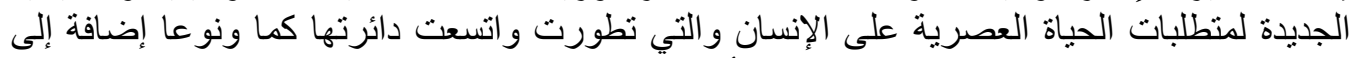

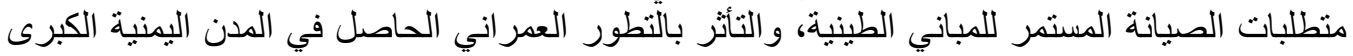

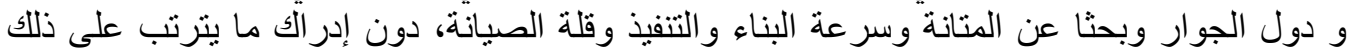

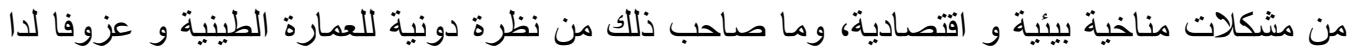

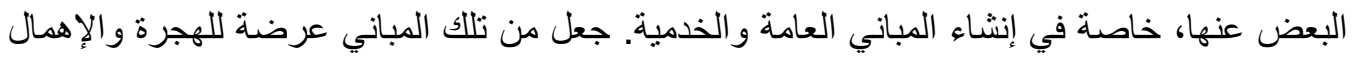

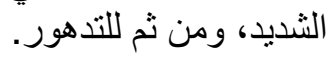

\section{ا ــ الإشكالية البحثية}

أظهرت العمارة الطينية قدرتها على مواءمة الخصائص البيئية ببعديها الطبيعي و الاجتماعي لقرون

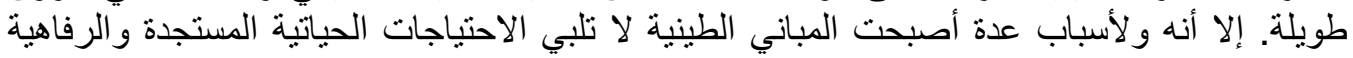

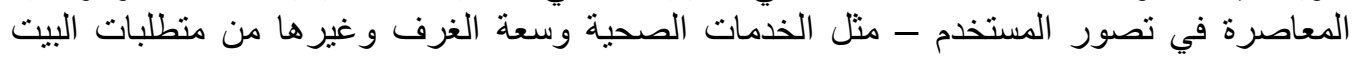

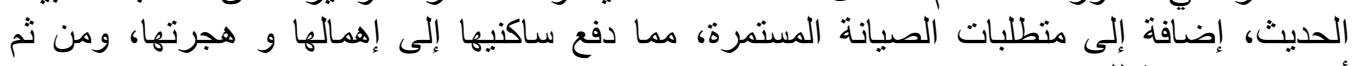

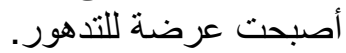

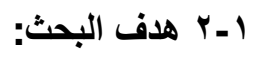

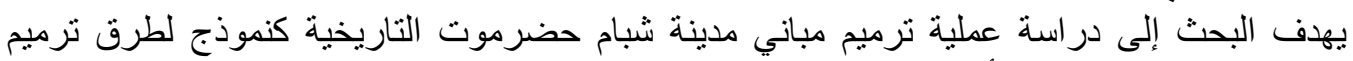

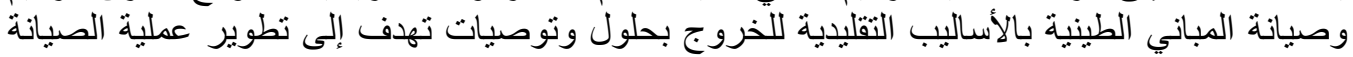
و التحديث للبيت الطيني بمنهاج علمي رصين للاستفادة منه وظيفيا للين وسياحيا. 


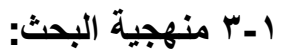

أعتمد البحث على الدراسة النظرية و التطبيقية لأساليب الترميم التقليدية والحديثة و على الدراسة التوثيثة وتيقية

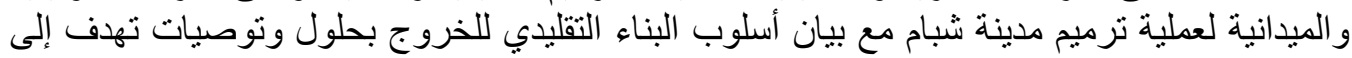
تطوير عملية صيانة وتحديث للبيت الطيني.

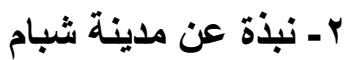

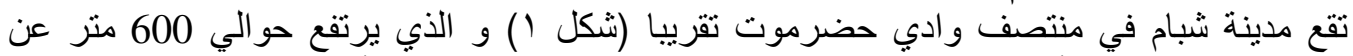

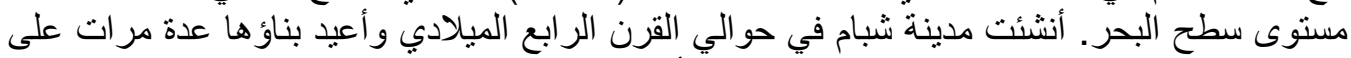

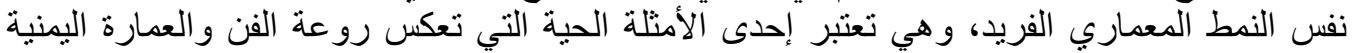

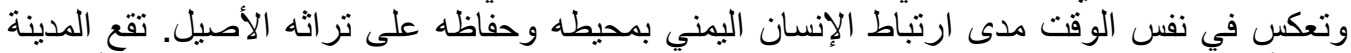

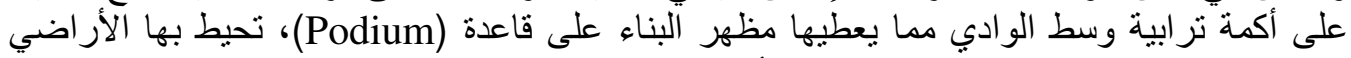

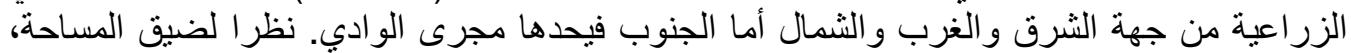

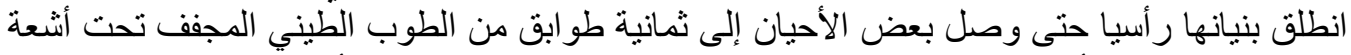

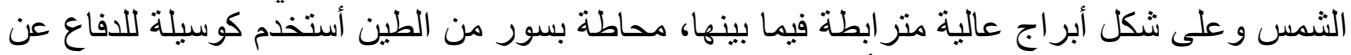
المدينة، وله بوابة واحدة من الطين أيضا تقع في الجهة الجنوبية الجية الثرقية الثنة من المدينة تفضي إلى ساحة

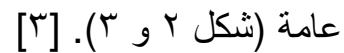

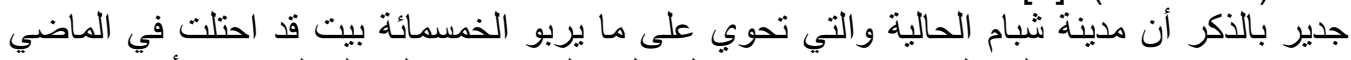

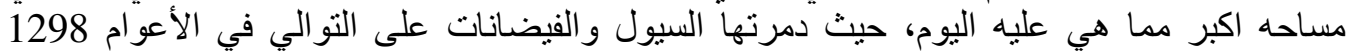
1562-1532-

\section{بـ الأضرار العامة التي تتعرض لها المباني الطينية}

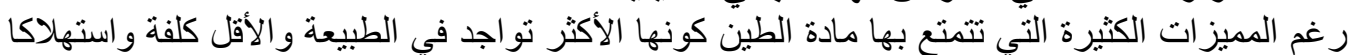

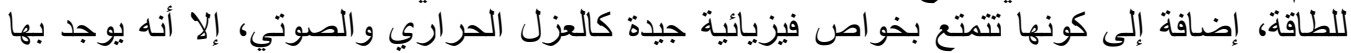
سلبيات ذات أسباب طبيعية و أخرى بشرية.

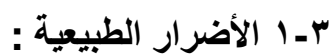
يمكن حصر الأضرار الطبيعية في عوامل فيزيائية كعوامل التعرية المختلفة وكيميائية كالرطوبة المباية

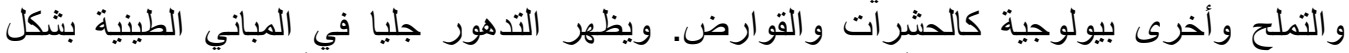

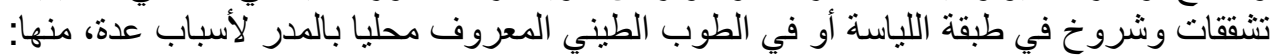

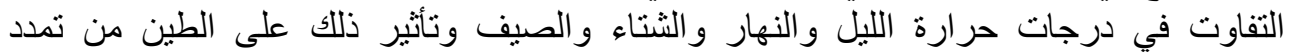

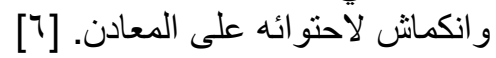

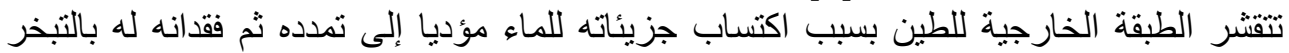

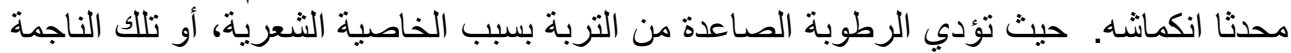

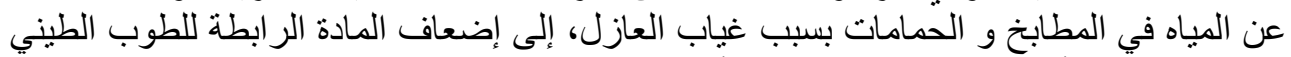

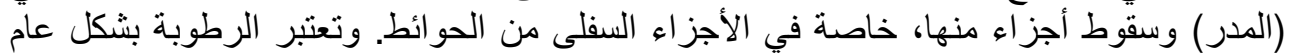

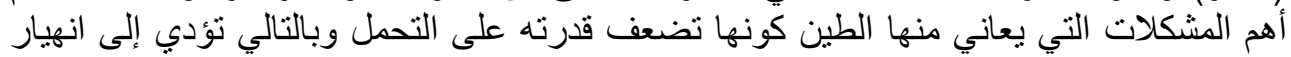

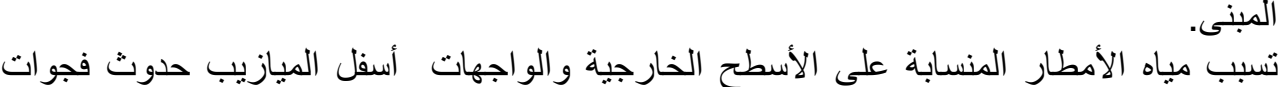

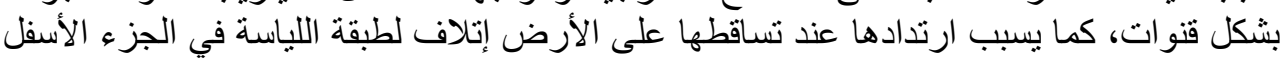

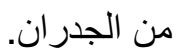
تآكل الطبقة المغلفة للحوائط (طبقة اللياسة) بفعل الرياح المحملة بالرمال العالية الصلابة. 


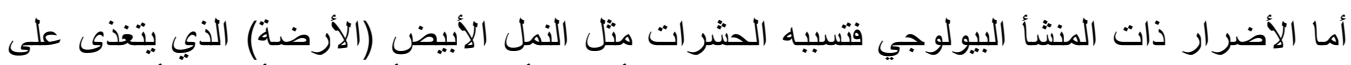

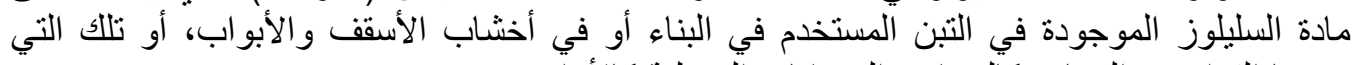
تسبيها القو ارض الضارة كالفئران والتين الحيو انات المنزلية كالأر آنب.

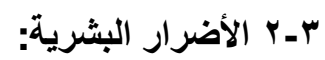

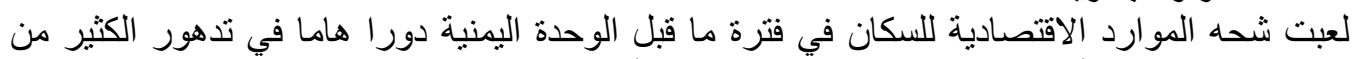

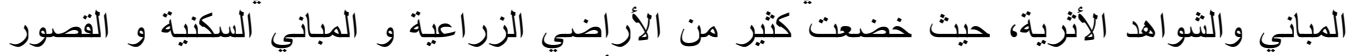

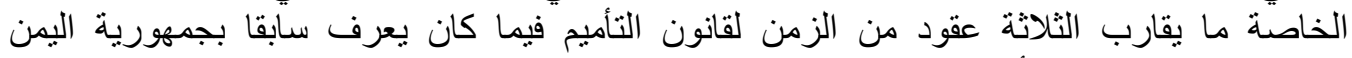

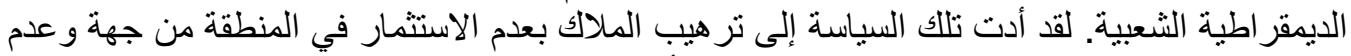

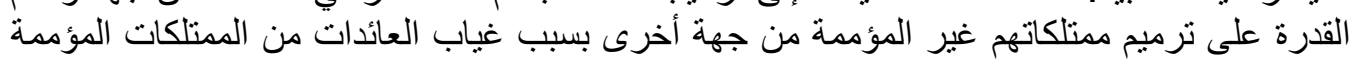

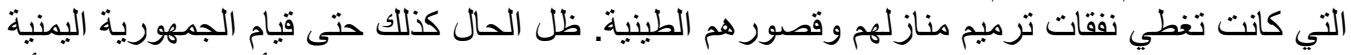

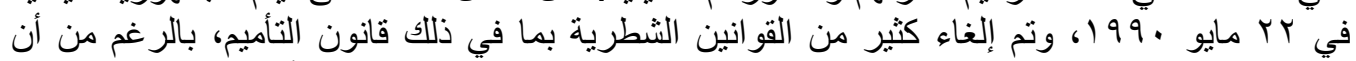

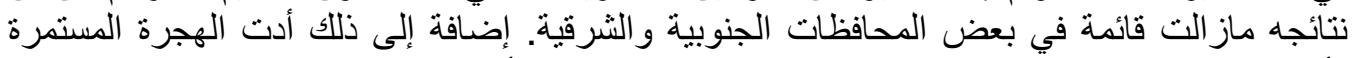

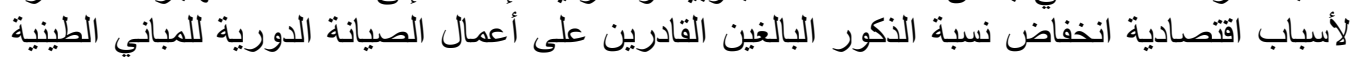

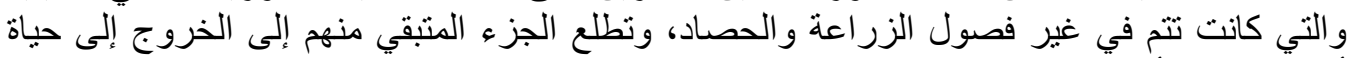
أكثر رفاهية و أقل جهد، إلى في إهمال هذه المبان المباني.

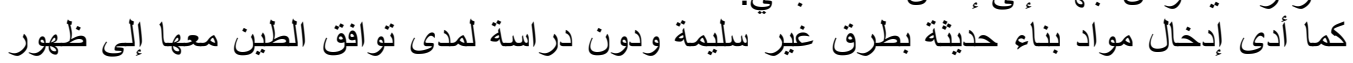

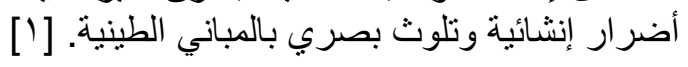

\section{ع - مشاريع صيانة وترميم المباني الطينية لمدينة شبام التاريخية}

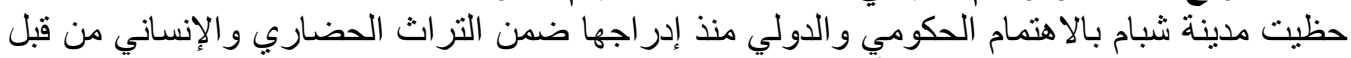

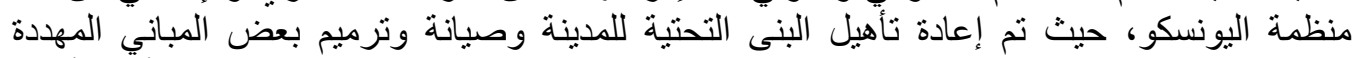

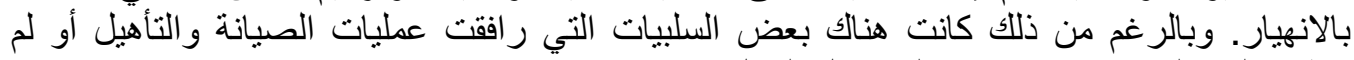
تنظرق لها بالدر استة نذكر منها على سلى سبيل المثال: شق الطريق الثرياني بمحاذاة أسوار المدينة الجنوبية الثبالية وما تسبيه حركة النقل المستمرة من

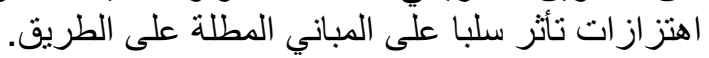

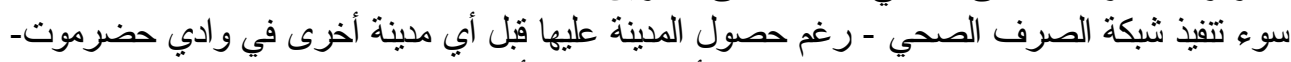

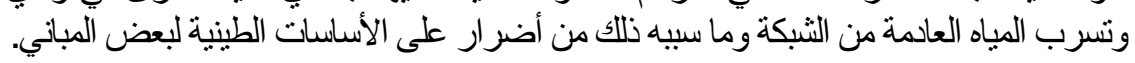

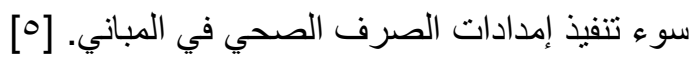

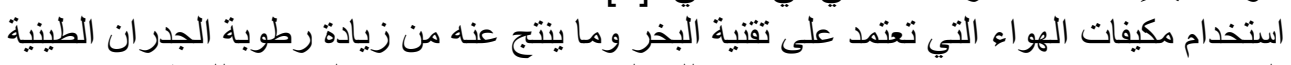

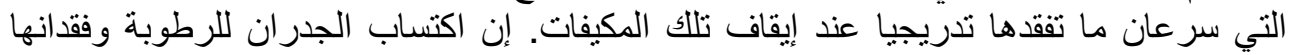

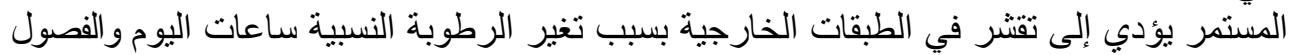

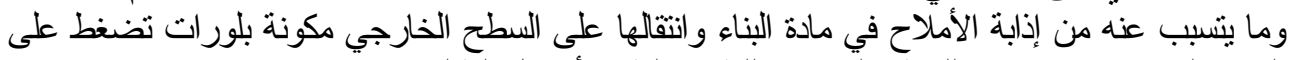
القنرة الخارجية محثية تفتنا للسطح الخارجي للطوب الطناة الطيني أو كتل الطفلة.

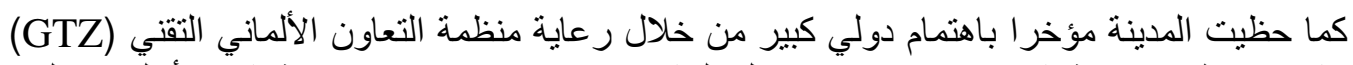

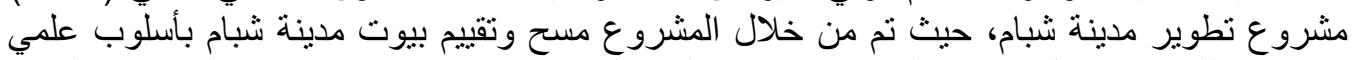

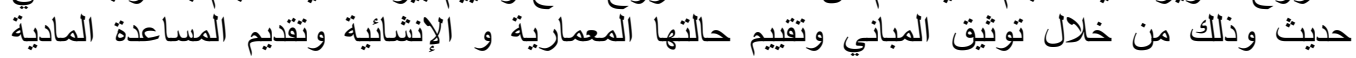

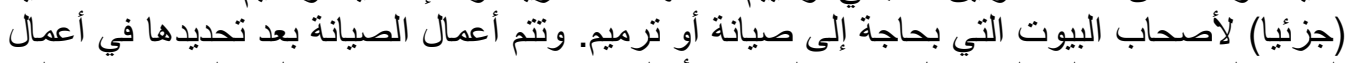

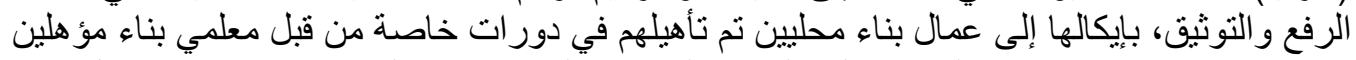

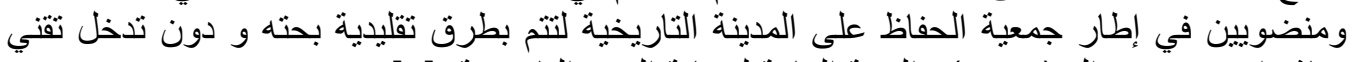
وبإثر اف مهندسي ال (GTZ) و الهيئة العامة لحماية الددن التاريخية. [0] 


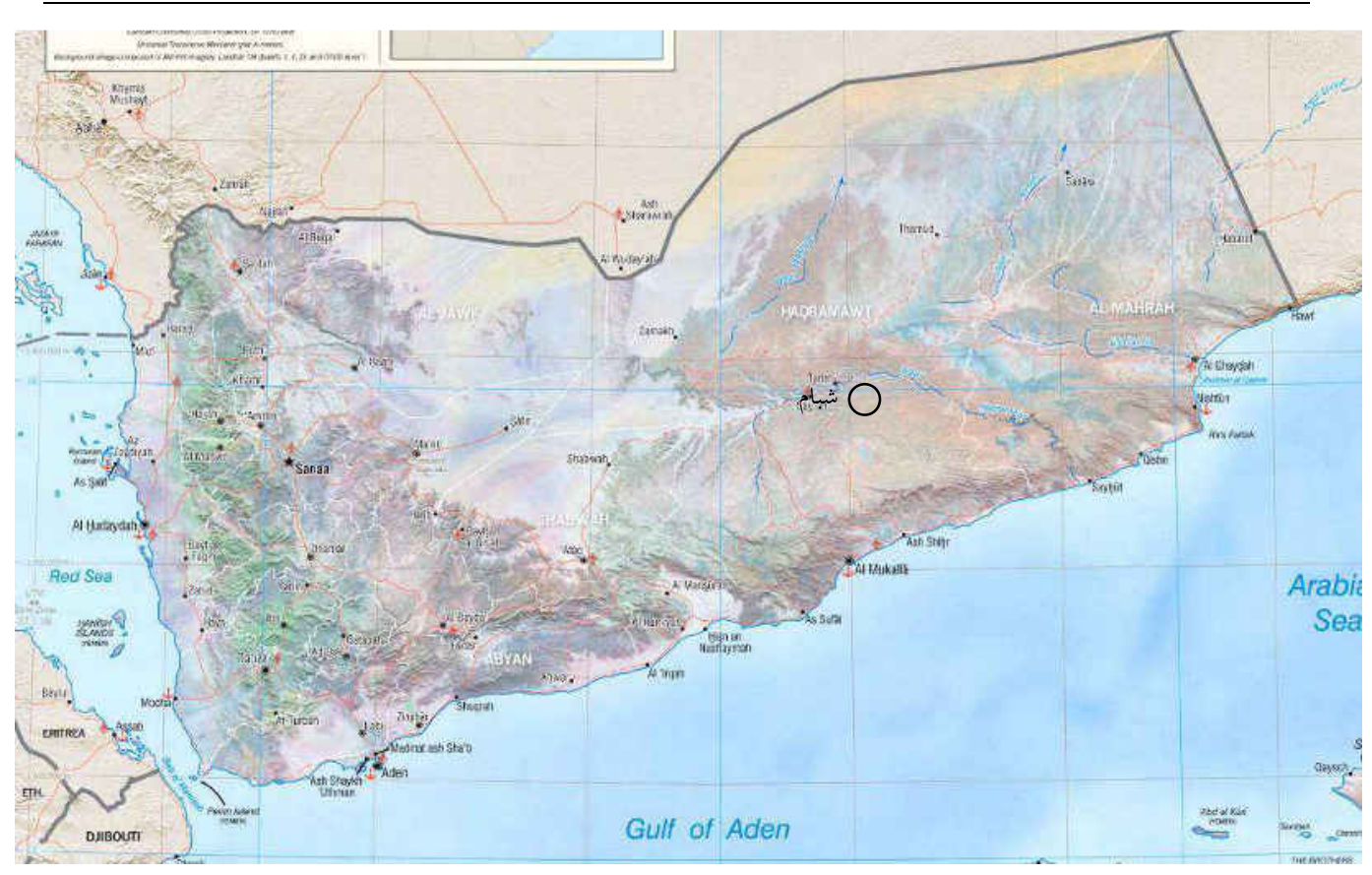

شكل ا:خريطة توضح مدينة شبام التاريخية من الجمهورية اليمنية.

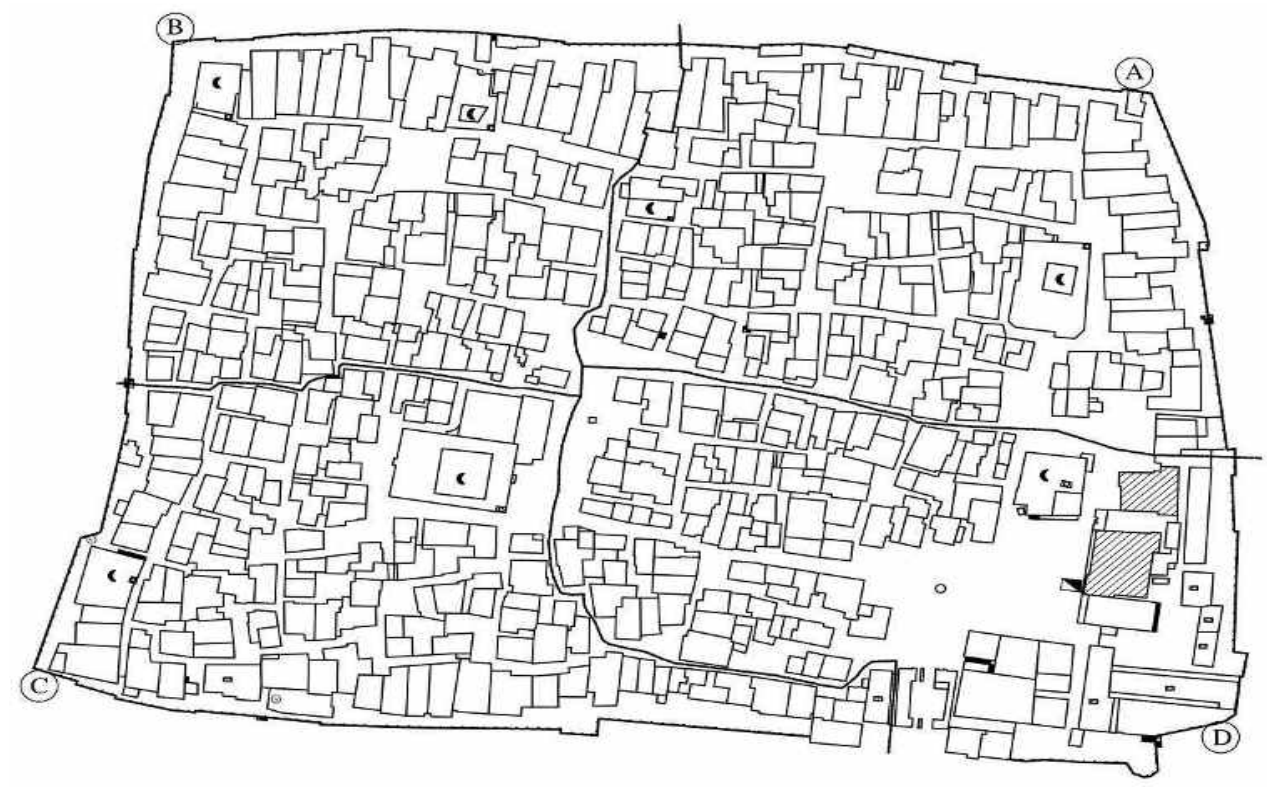

شكل r: خريطة لمدينة شبام التاريخية، مقسمة إلى أربعة مناطق (A-B-C-D) لتسهيل عملية نوثيقها.[0] 


\section{هـ طرق البناء و المعالجة لمباني شبام}

0ـ 1 الأسـاسات

تبنى الأساسات غالبا من الطين النيئ (وحدات من الطوب الطيني المجفف بأثعة الثمس) وفي مناطق

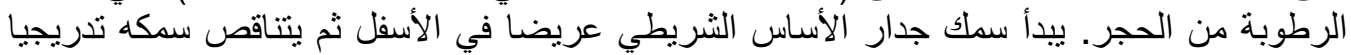

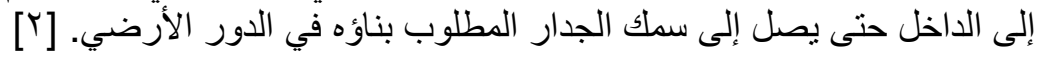

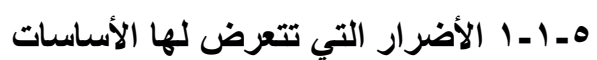

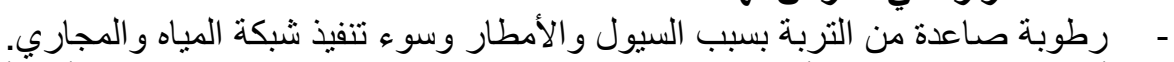

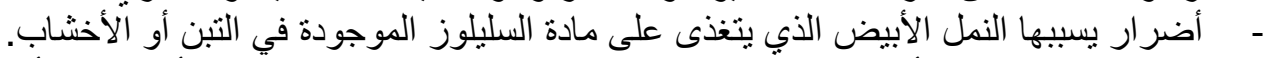

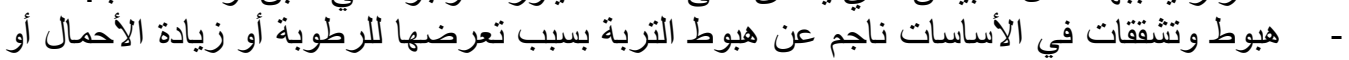
سوء تصريف مياه الأمطار.

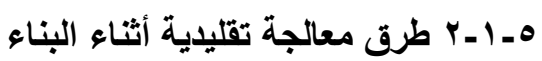

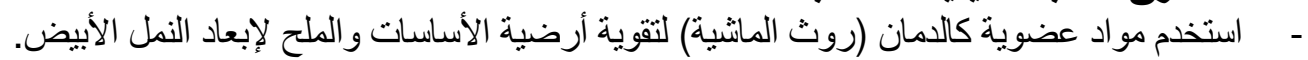

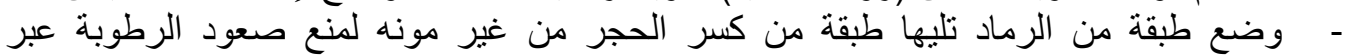

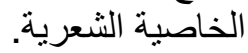

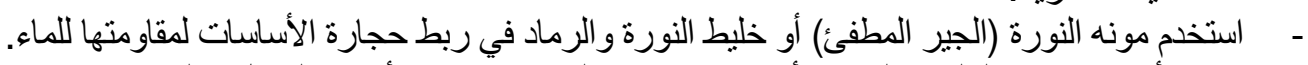

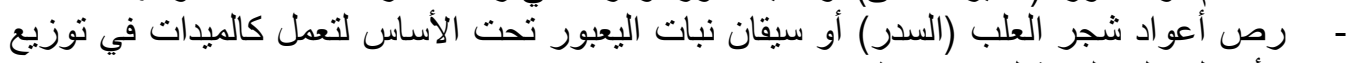
الأحمال على التربة لتمنع هبوطها.

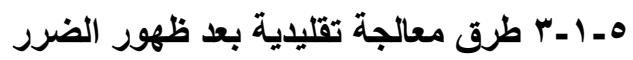

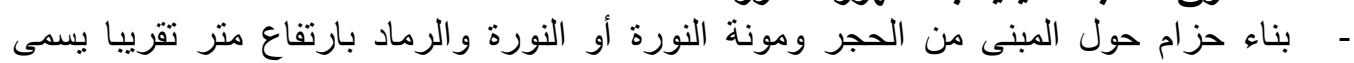

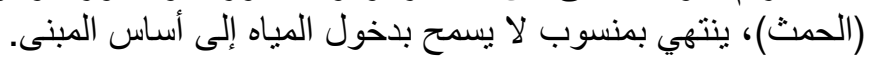

هـ - ـ ـ استخدام طرق ومواد بناء مستحدثة في العمارة الطينية

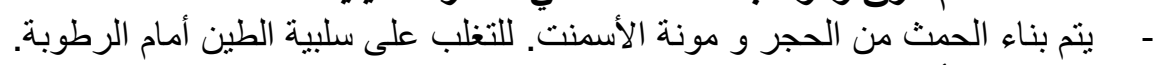

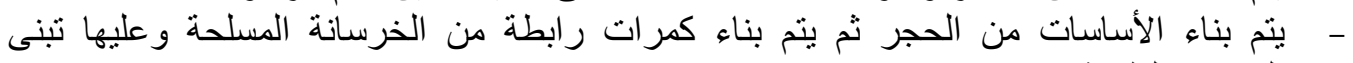

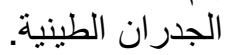

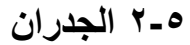

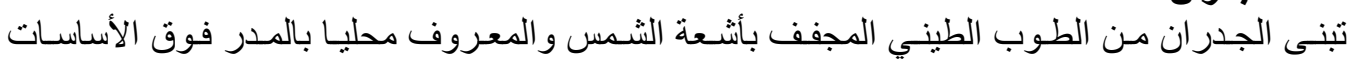

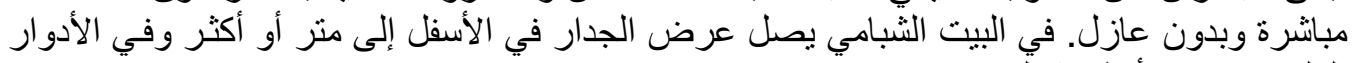

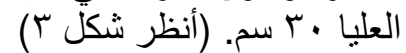

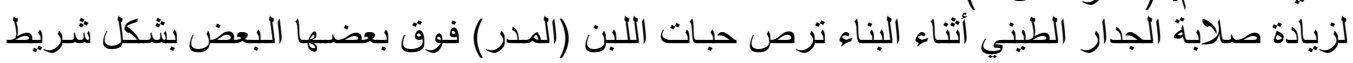

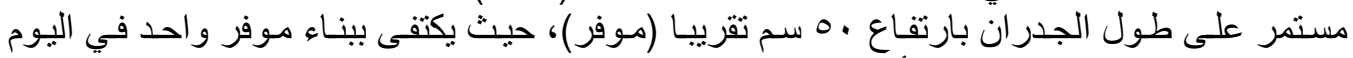

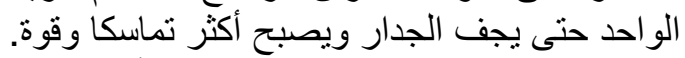

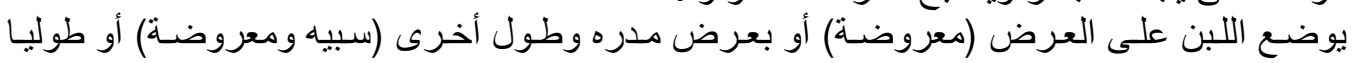
(سبيه) بحسب سمك الجدار.

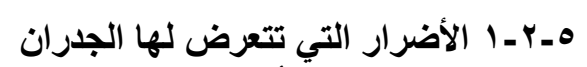

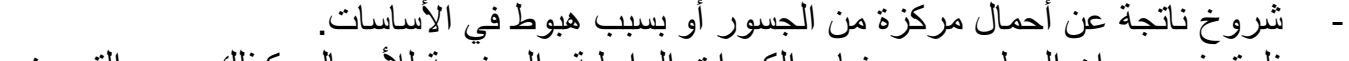

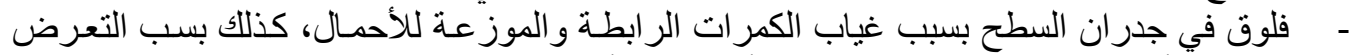
للارطوبة أو ضعف قوة الطوب المستخدم أو زيادة الأحمال. 


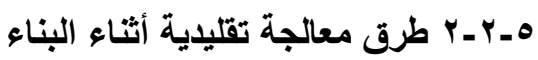

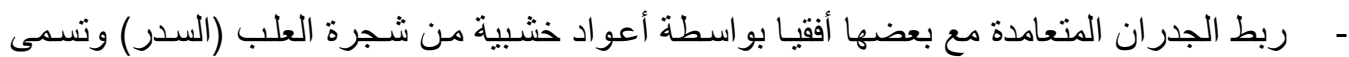
هذه العيدان (البسوط)، وتعمل البسوط على تقوية الروابط بين الجدران من جهة وتوزيع الأحمـال عليها

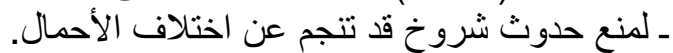

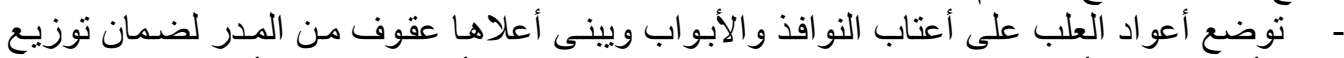

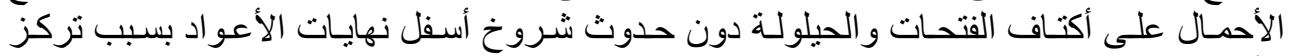
الأحمال. الأ.

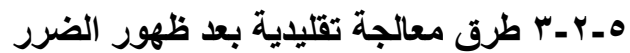

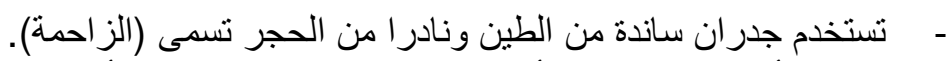

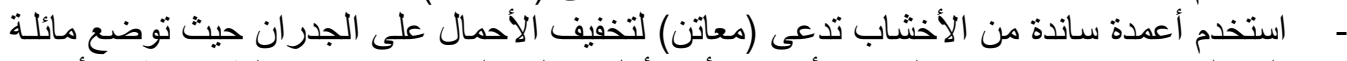

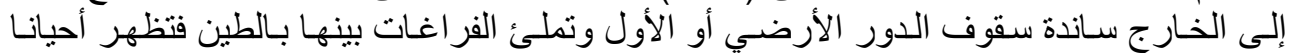

$$
\text { بشكل الز احمة. }
$$

- تعبئة الفتحات والثرة الثروخ في الجدران بمونة الطين مع التبن.

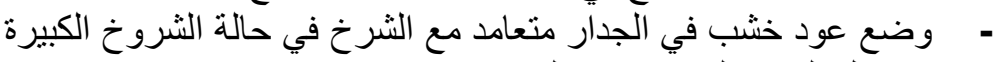

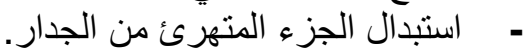

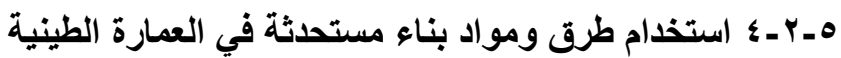

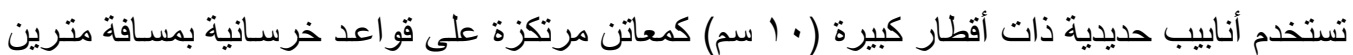

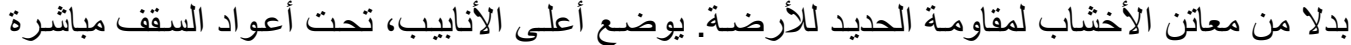

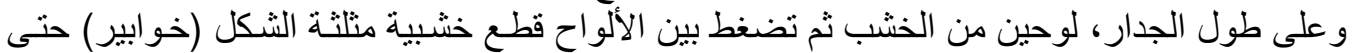

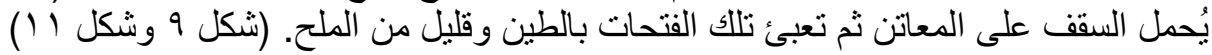
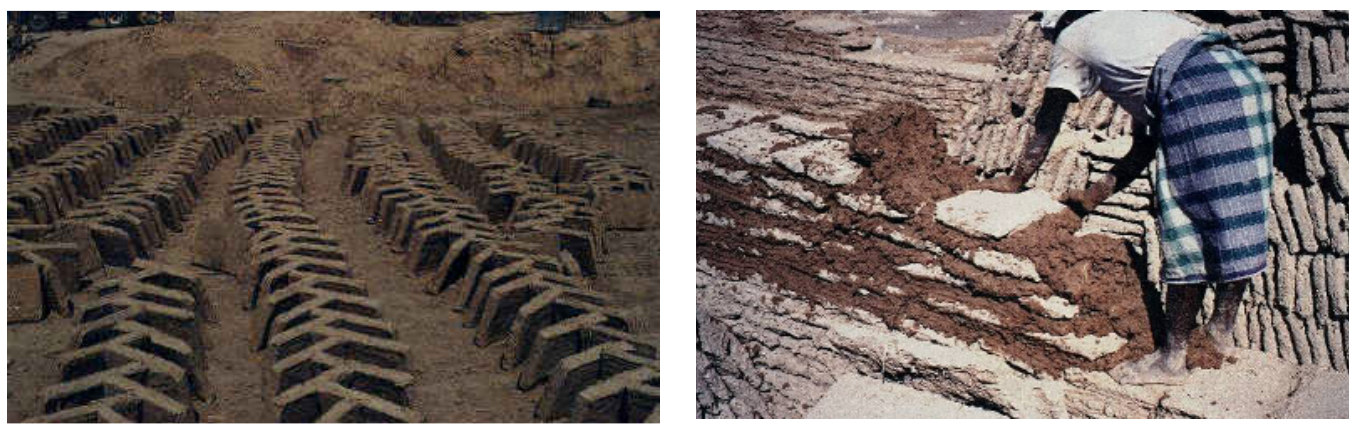

شكل r: البناء التقليدي بالطوب الطوب الطيني المجفف بواسطة أشعة الثمس والذي يسمى محليا (بالمدر) (الصورة إلى اليمين)، طريقة رص البطوب المدر جانبيا لتجفيفه (الصورة إلى اليسار).

\section{P السقوف}

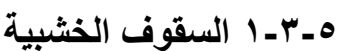

توضع أعو اد أخشاب العلب (السدر) على الجدران الطينية الحاملة مباثرة وتسمى (القبال). ونتيجة لقصر ها

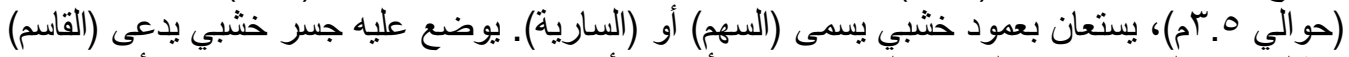

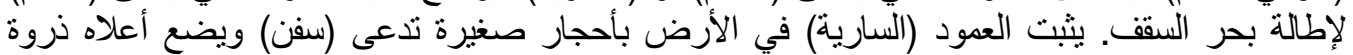

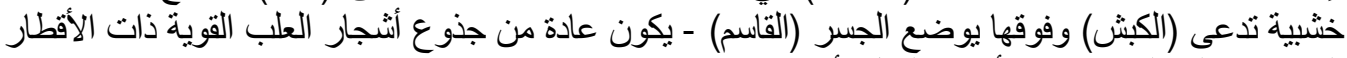

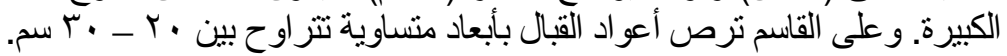


في الأسقف المزخرفة ترص على القبال عيدان صغيرة لنبات العثر أو الأر الك بدقة متناهيـة بأنثكال

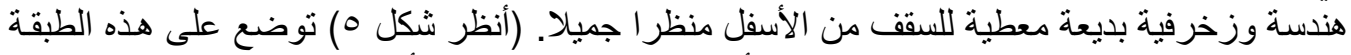

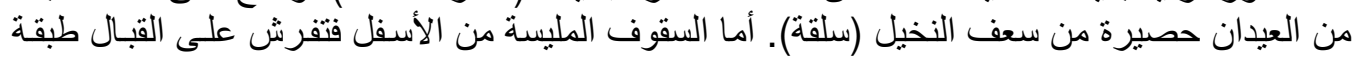

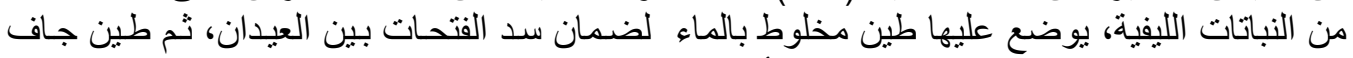

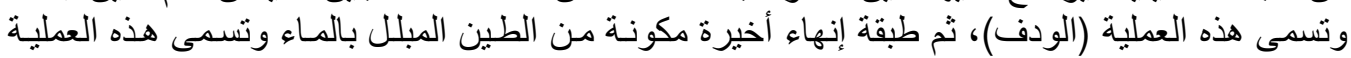
بمحضة السقف.

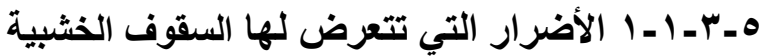

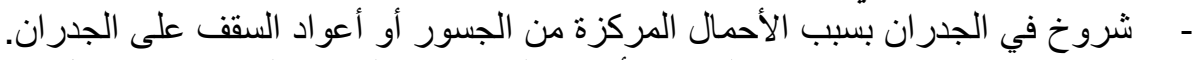

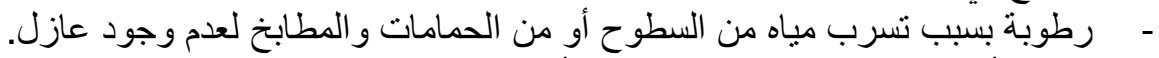

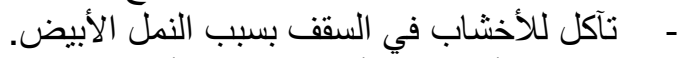

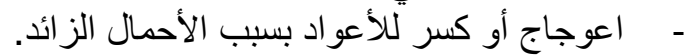

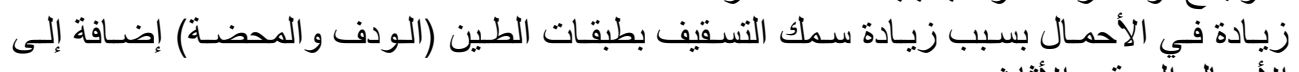

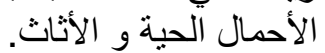

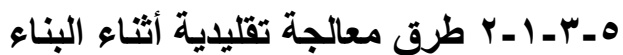

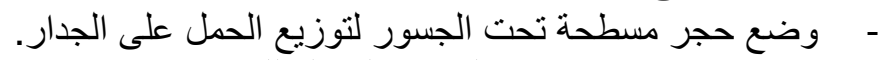

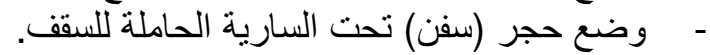 \\ - - - استخدام العيدان الكبيرة الجافة للأعمدة و الجسور و والسقوف.

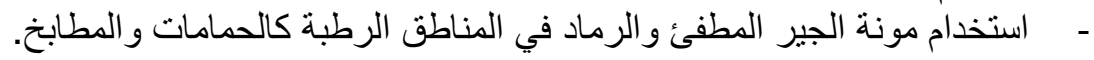

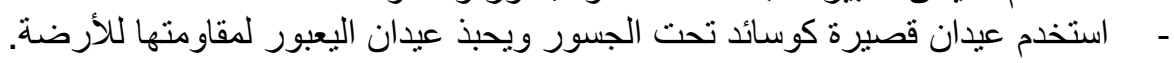

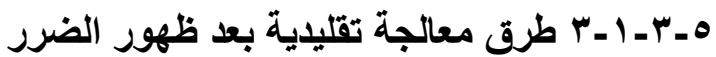

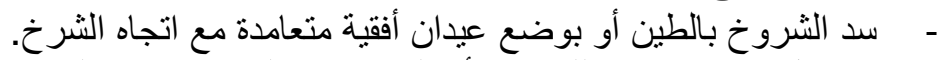

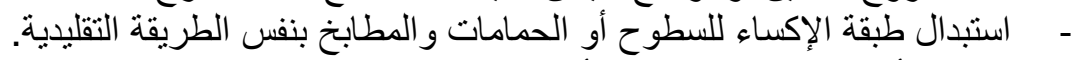
- - استبدال أعو اد الخشب المصابة بأخرى جديدة عادة دون معالجة.

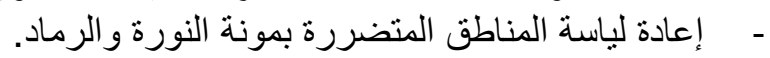

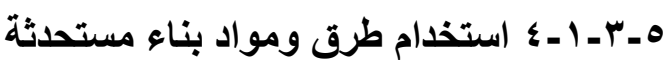

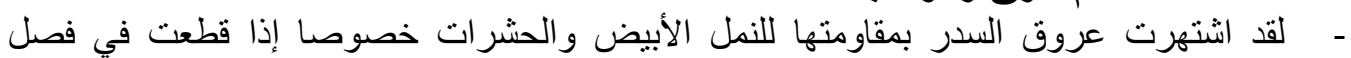

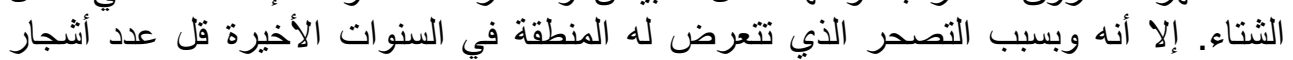

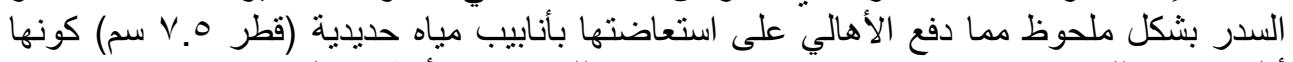

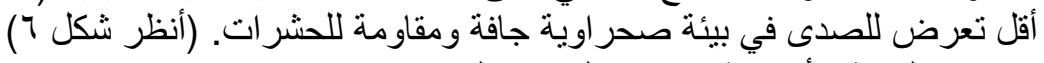

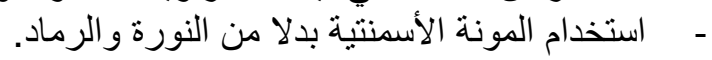

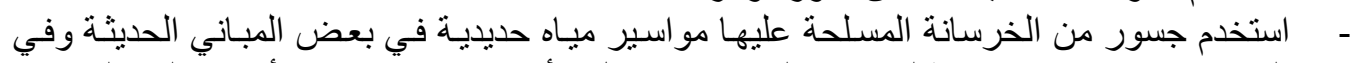

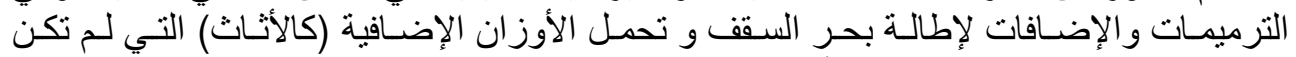

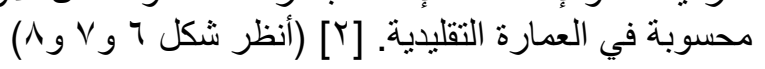

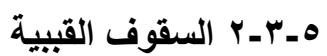

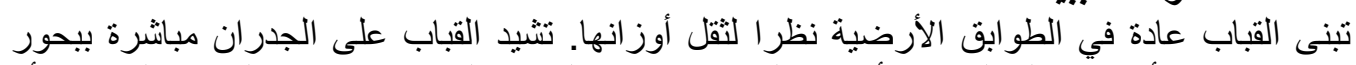

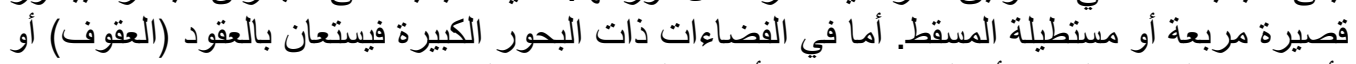

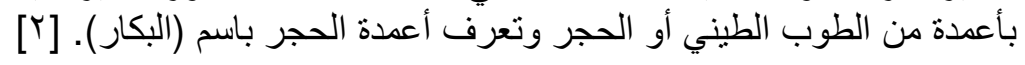

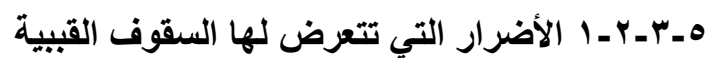

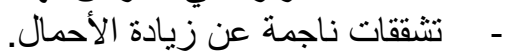


- انهيار بسبب تتضرر الجدران والأكتاف الحاملة و عدم القدرة على مقاومة القوى الر افسة.

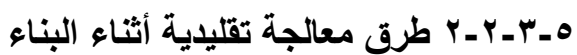

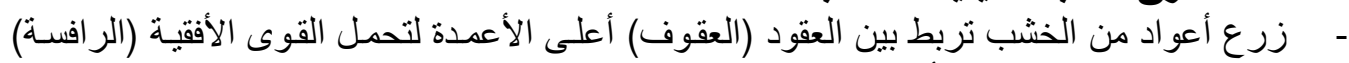
ولتقليل سماكة الجدر ان واعن الأعمدة الحاملة للقباب.

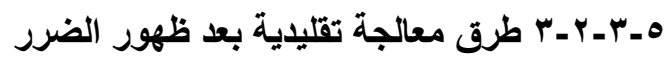

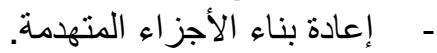

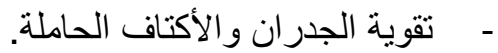

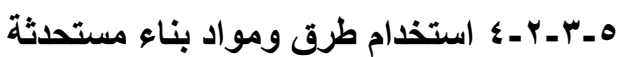

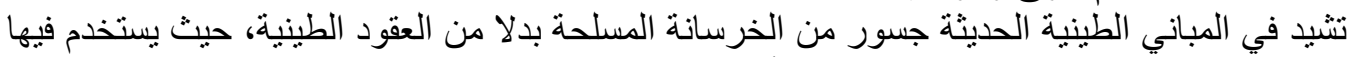

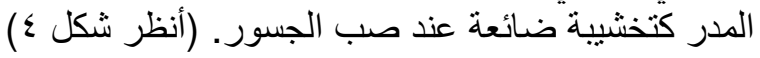

هـ ـ السطوح ومناطق الرطوبة (الحمامات و المطابخ)

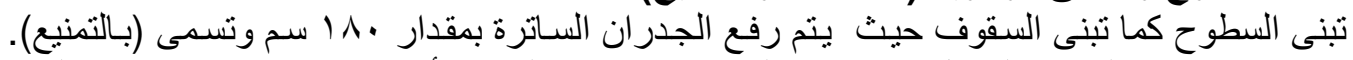

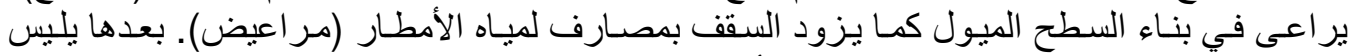

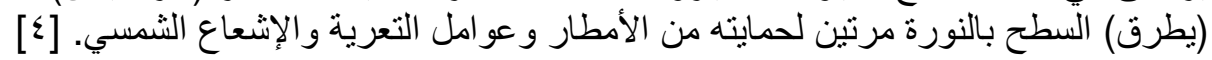

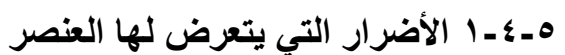

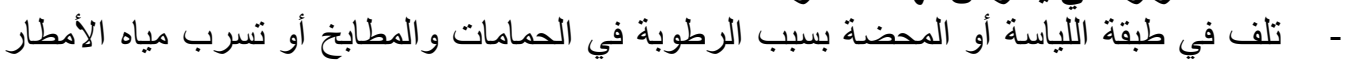
من السطوح. - شروخ سطحية إلى عميقة لعدم التوزيع المتساوي للأحمال على الأسطح.

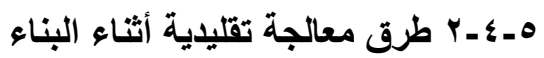

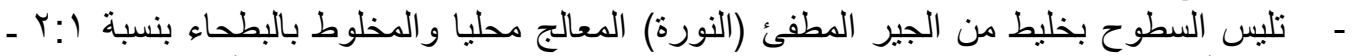

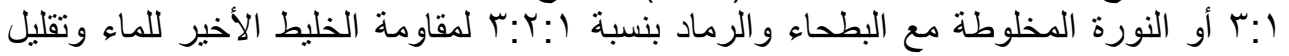

$$
\text { نسبة انكماش النورة. }
$$

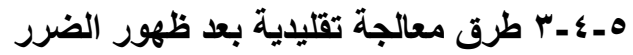

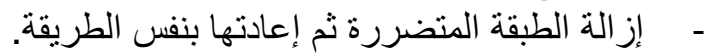

هـ ـ ـ ـ استخدام طرق ومواد بناء مستحدثة في العمارة الطينية

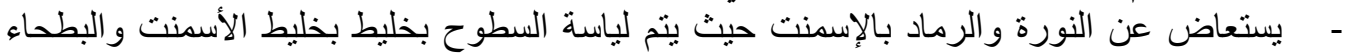

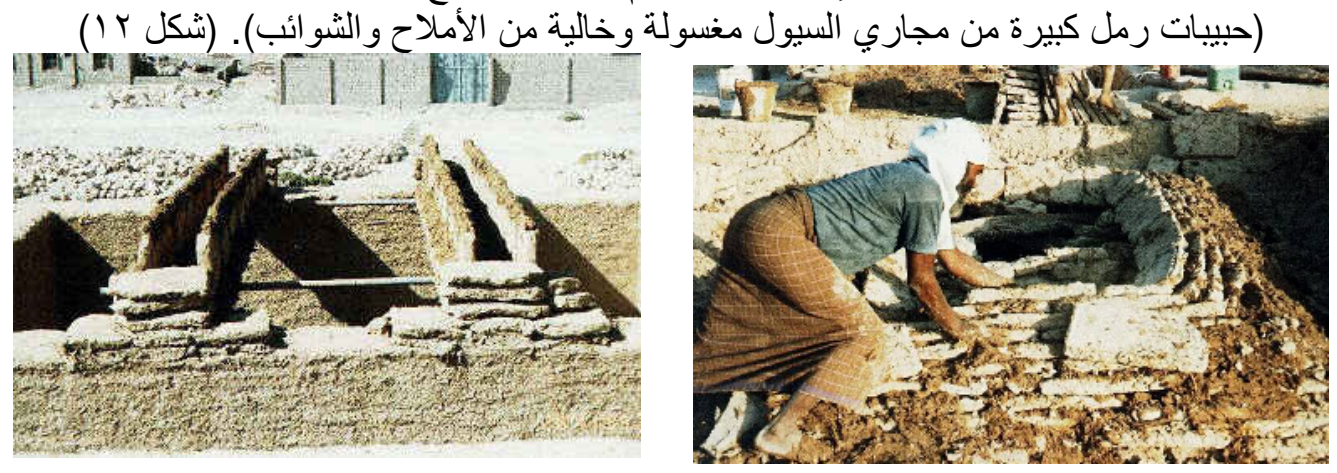

شكل ؟: طريقة التسقيف بواسطة القباب (الصورة إلى اليمين)، تقنية بناء التخثيبة الضائعة من المدر لجسر خرساني ستبنى عليه لاحقا قبة نصف أسطو انية من الطين، الصورة الئنة إلى اليسار) 

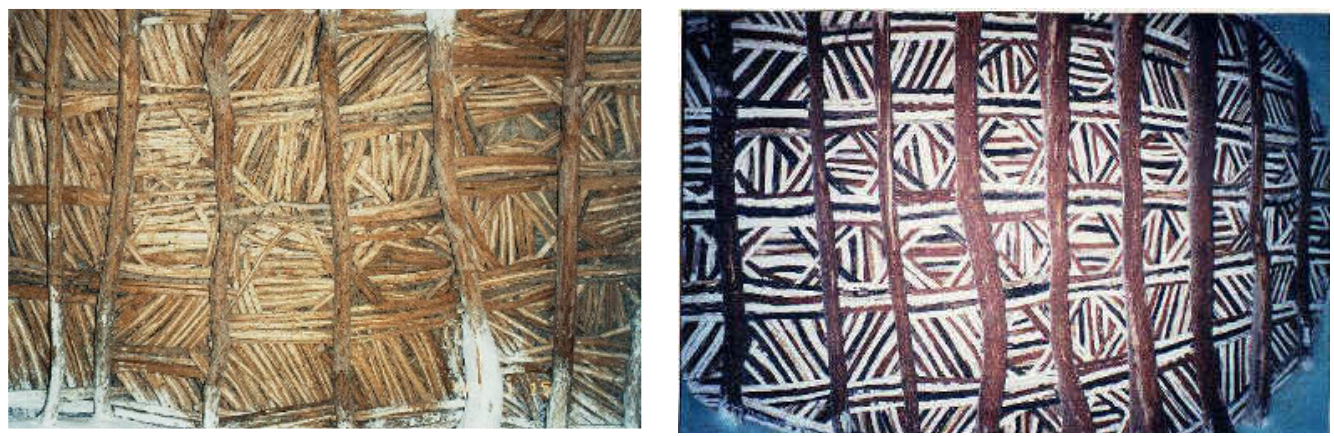

شكل 0: منظر لسقف تقليدي من الداخل تظهر فيه أعو اد العلب و نباتات العشر معمولة بطريقة زخرفية بديعة.
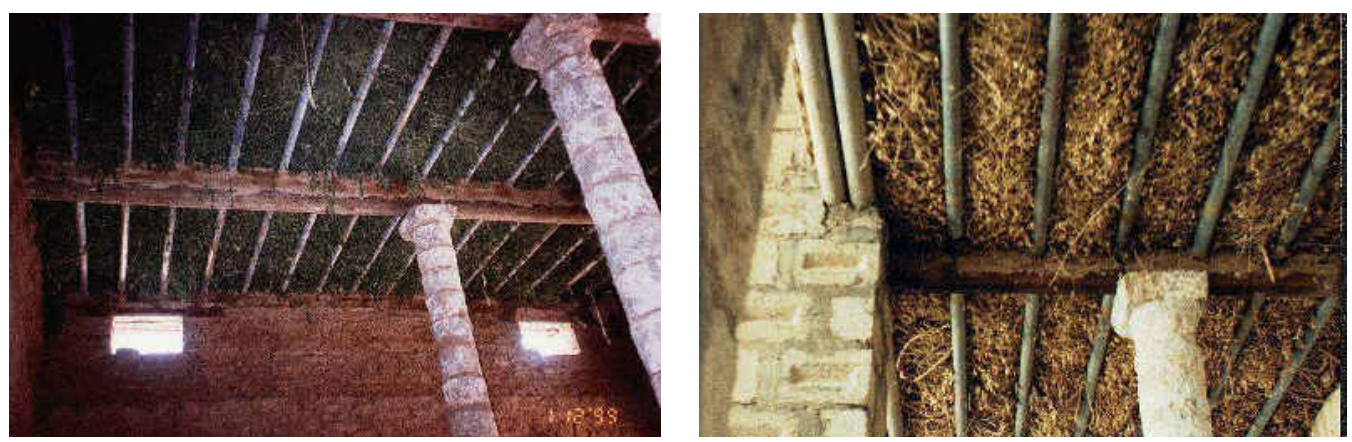

شكل 7: استخدام مواسير المياه الثبيهة بأعواد الأشجار ذات الأقطار الدائرية في تسقيف المباني الطينية، كما يلاحظ استخدام الطوب الخرساني بدلا من الطوب الطئي الطيني في بناء الأعمدة.
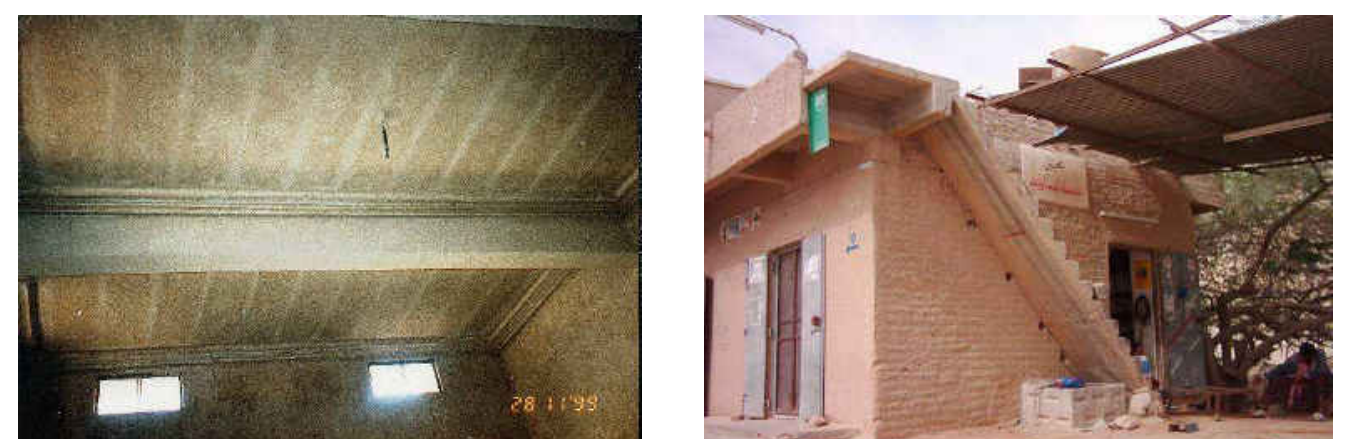

شكل ₹: استخدام الخرسانة المسلحة في بناء السلالم و الجسور لإطالة بحر الأسقف في العمارة الطينية. 

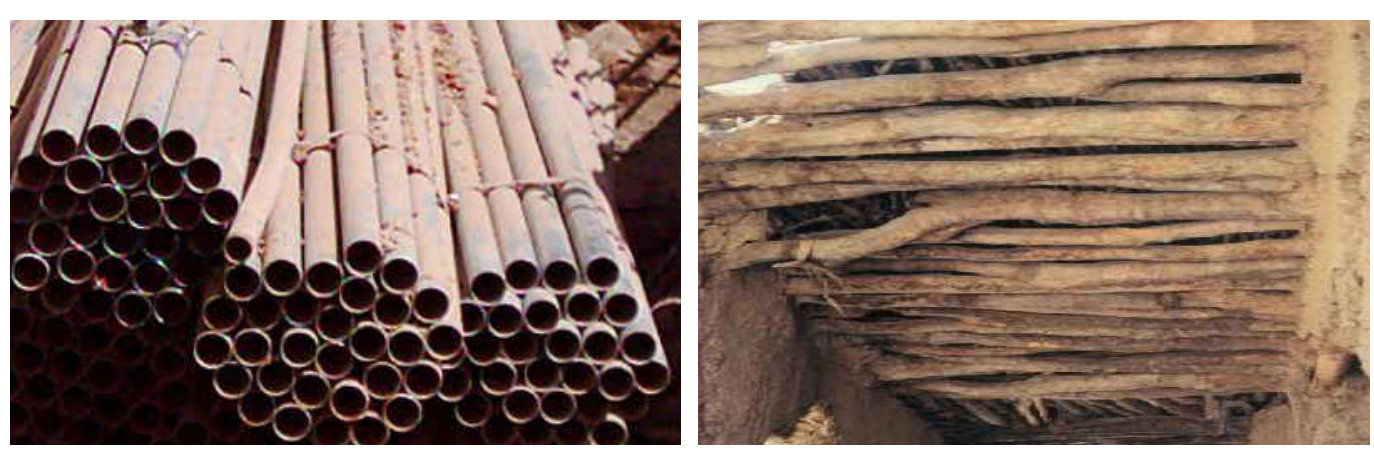

شكل ^: استخدام الأهالي مواسير المباه الثبيهة بأعواد الأشجار ذات الأقطار الدائرية في تسقيف مبانيهم لتقارب الصورة البصرية بينهما.
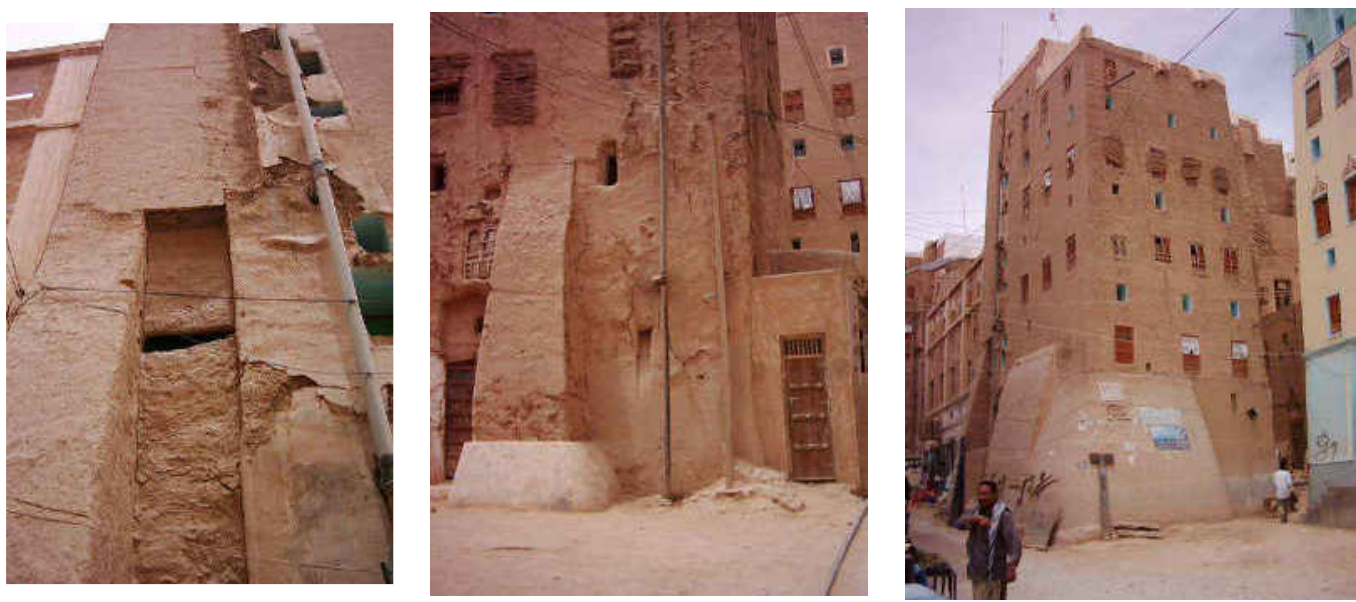

شكل 9:التلوث البصري الناشئ من استخدام طريقة الإسناد الخارجي للجدران والأسقف بواسطة

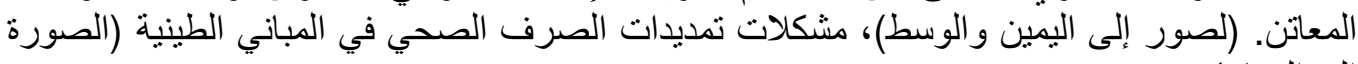
إلى اليسار). 


\section{هـ - أعمال البياض واللياسة}

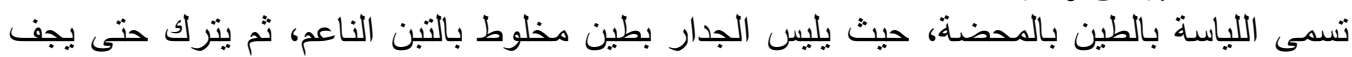

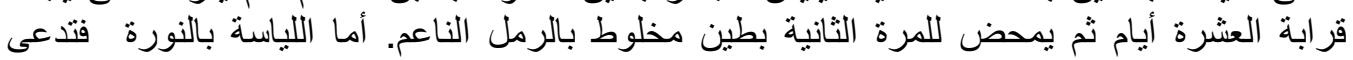

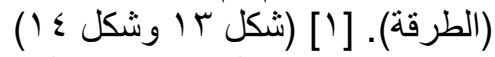

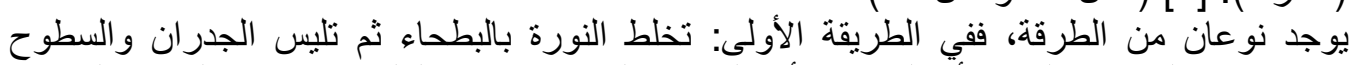

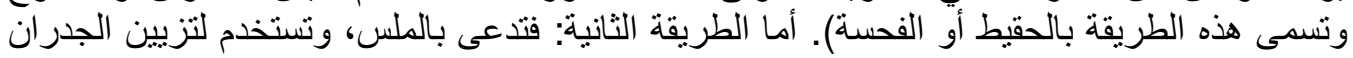

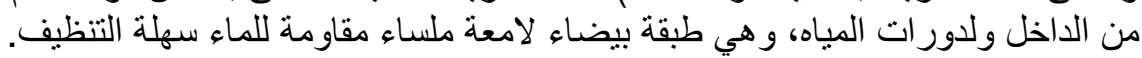

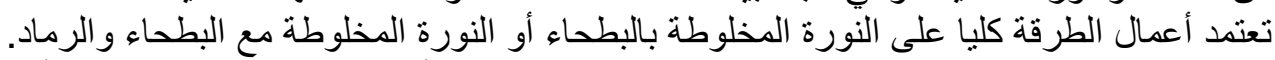

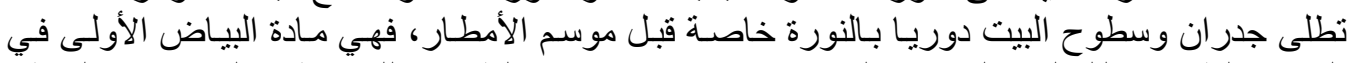

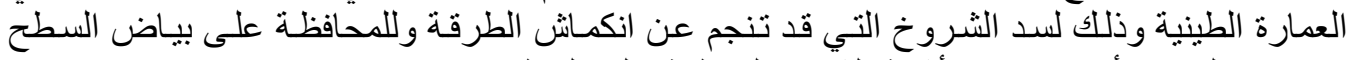

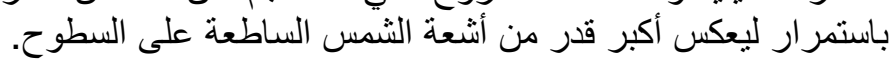

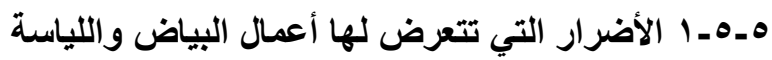

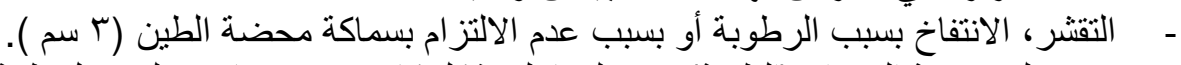

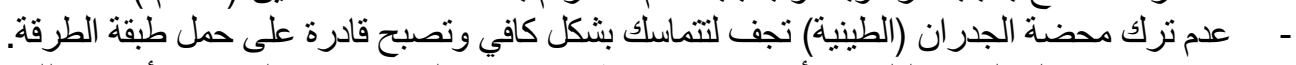

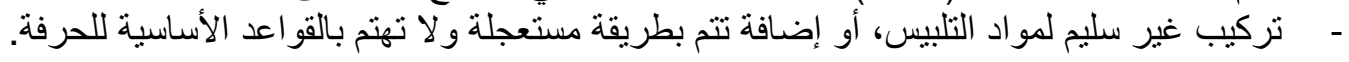

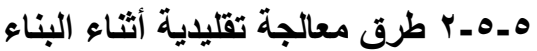

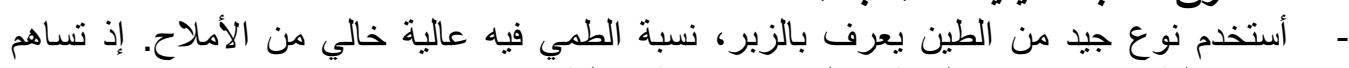

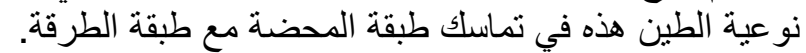

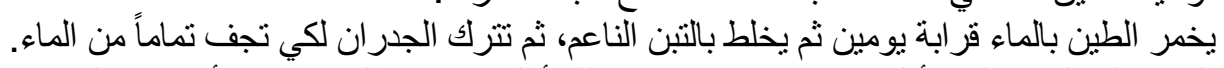

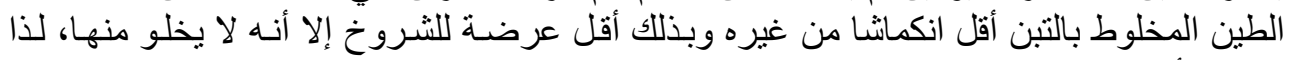

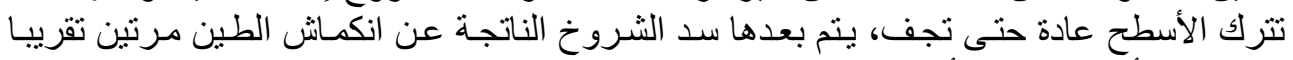
حتى يتم التأكد من خلو الأسطح منها.

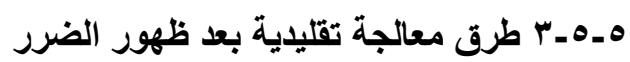

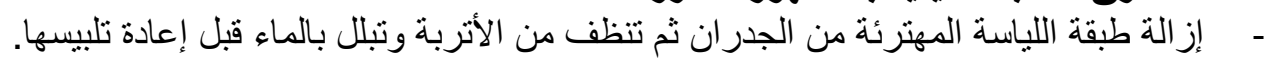

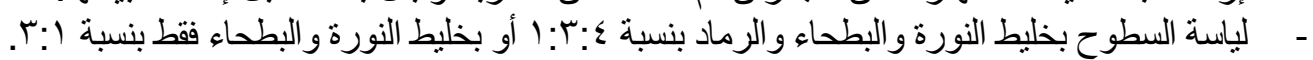

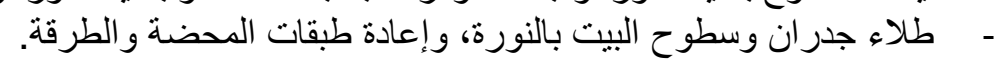

هــــ استخدام طرق ومواد بناء مستحدثة في العمارة الطينية.

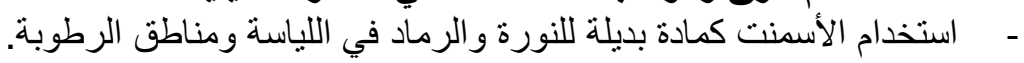

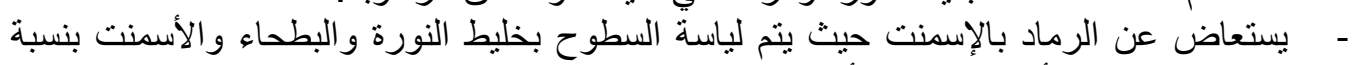

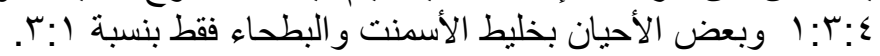

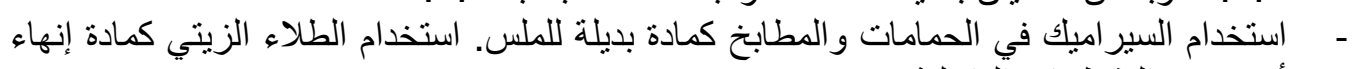
أخيرة في التشطيبات ألداخلية.

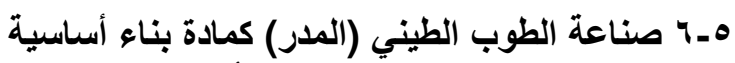

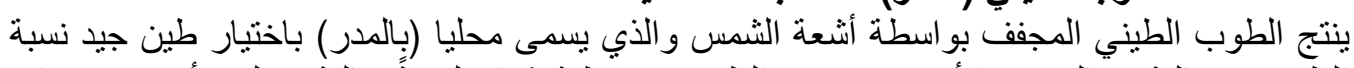

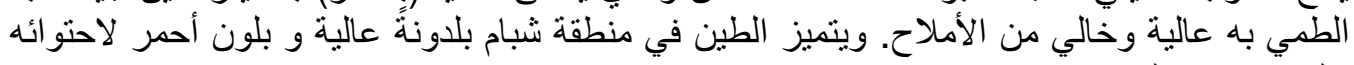

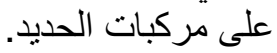

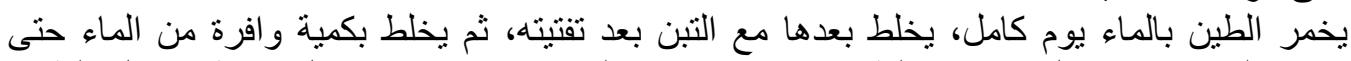

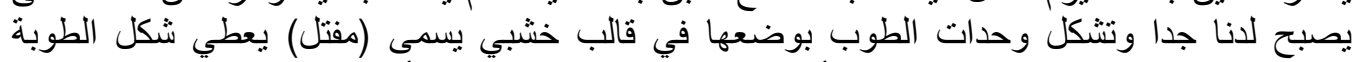

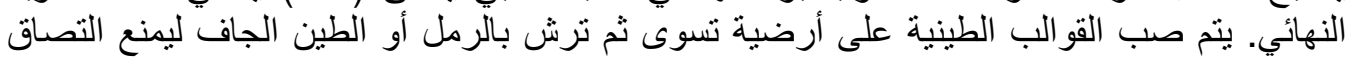


القو الب الطرية بالأرض. ينرك الطوب خمسة إلى سبعة أيام ليجف ثم يقلب ويرص عموديا ليجف أكثر

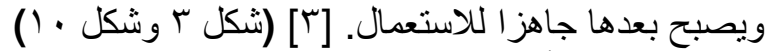
يوجد هناك ثناثة أحجام مختلفة من الطوب الطيني المجفف بواسطة أشنعة الثمس المستخدم في منطقة الدراسة

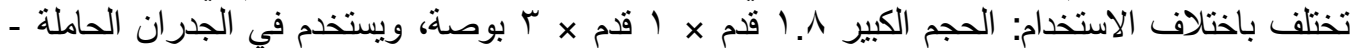

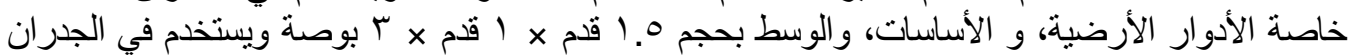

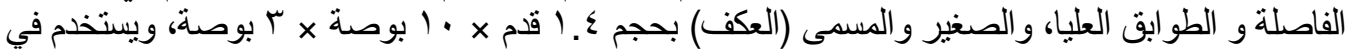
بناء القباب و العقود.

$$
\begin{aligned}
& \text { هـ ـ - الأضرار التي يتعرض لها الطوب الطيني }
\end{aligned}
$$

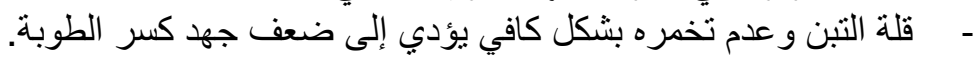

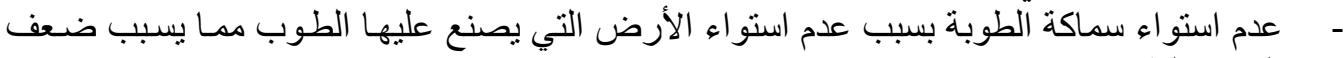

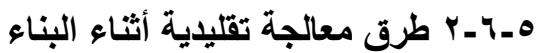
- يخمر الطين بالماء قر ابة اليومين، يخلط بعدها مع التبن بعد تفتيته، ثم يخلط بكمية وافرة من الماءه، أثناء

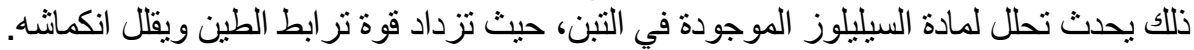

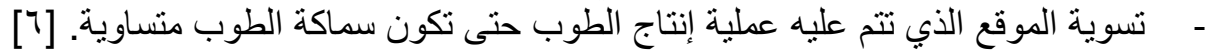

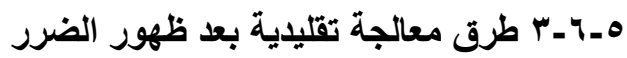

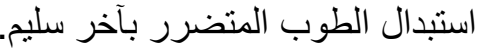
هـ - ـ استخدام طرق ومواد بناء مستحدثة في العمارة الطينية

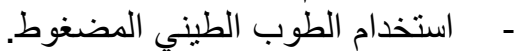
- - استخدام البلك الأسمنتي بدلا من الطوب الطيني. (شكل 7 (

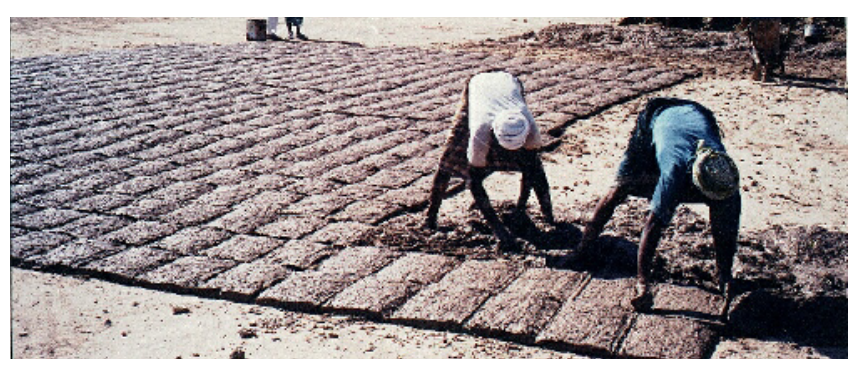

شـكل · إ: صـورة توضـح طريقة إنتاج الطوب الطيني المجفف بو اسطة

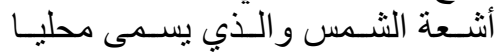

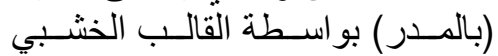



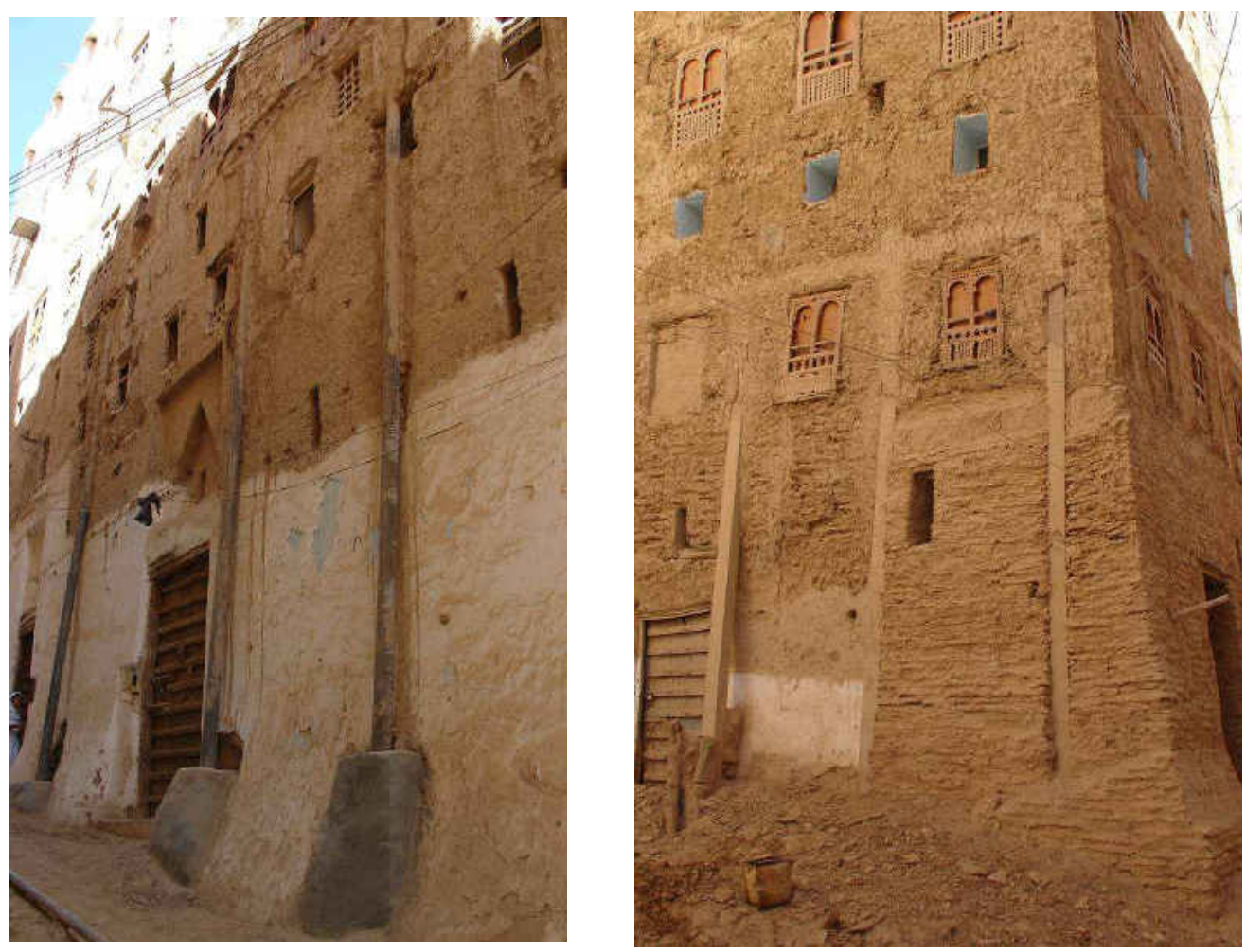

شكل / إ: إسناد الجدران بو اسطة أعمدة خشبية ـ معاتن من الخشب ــ الصورة إلى اليمين، و استخدام المواسير الحديدة حديثا ذات الأقطار الكبيرة كمعاتن.

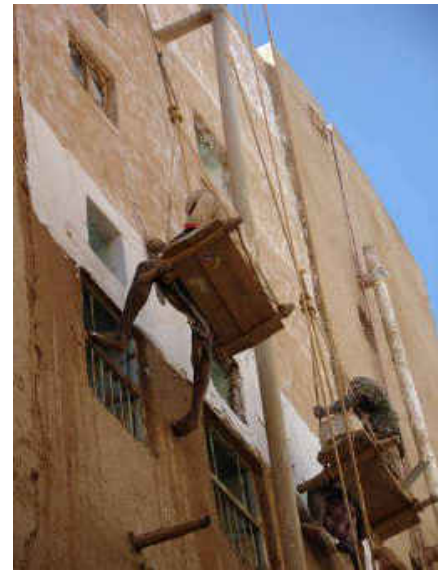

شكل ع ا: تبيض إحدى الو اجهات بالنورة.

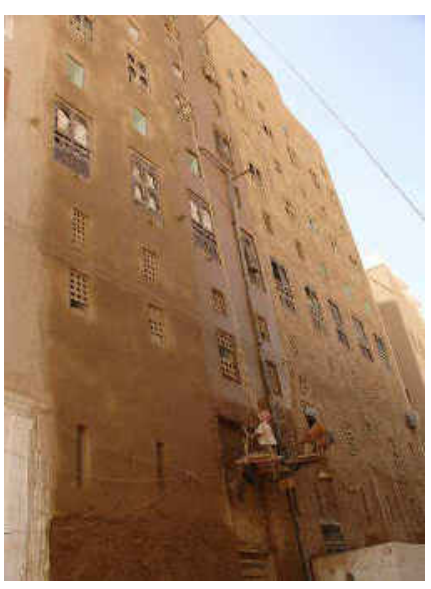

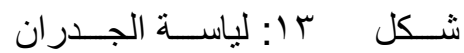
الخارجية بالطين (المحضة) ليالية

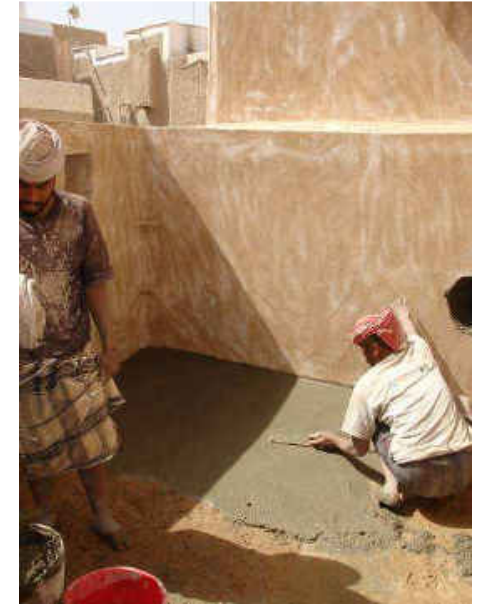

شكل r ا!: إنهاء السقوف حديثا بمادة

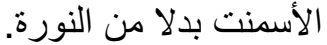


\- تطوير الأساليب التقليدية في تحديث البيت الطيني و صياتته

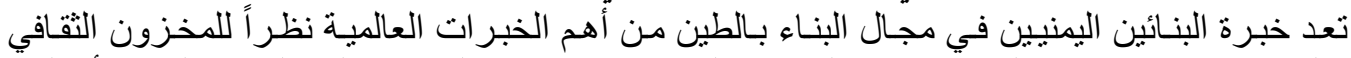

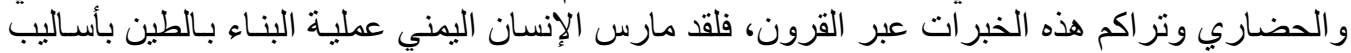

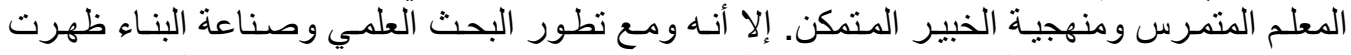

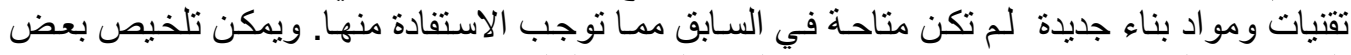

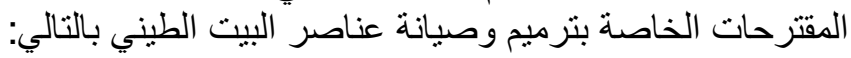

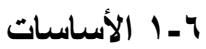

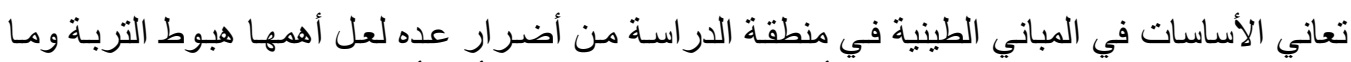

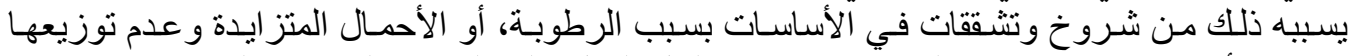

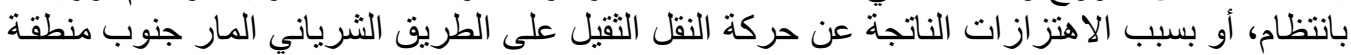

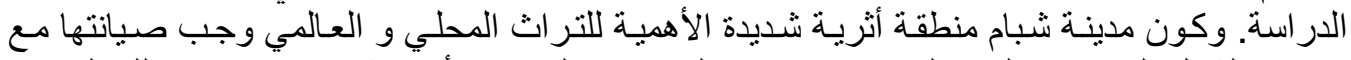

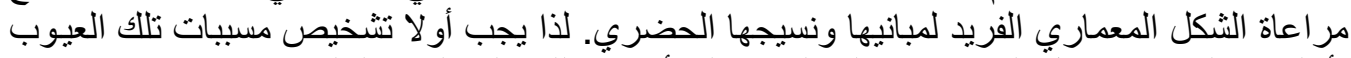

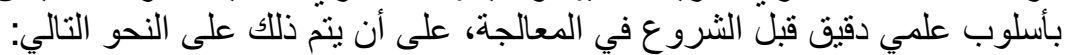

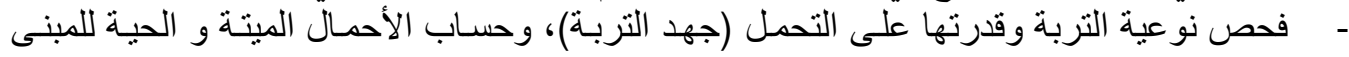

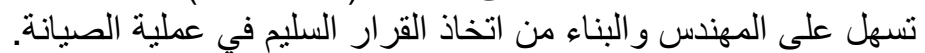

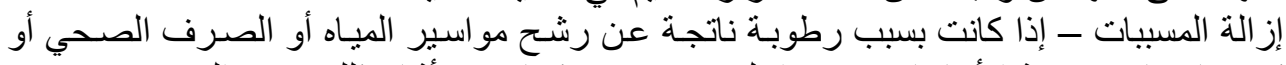

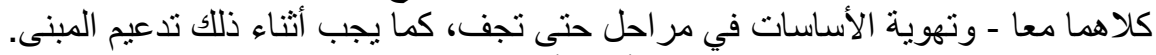

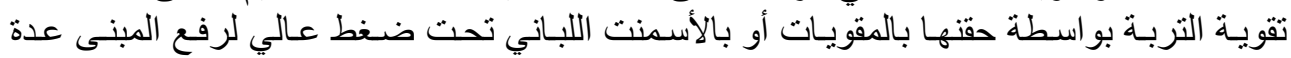

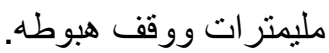

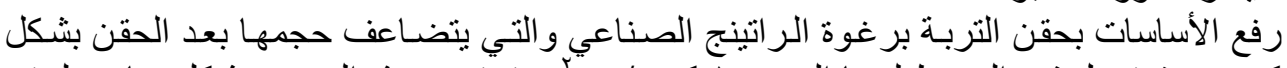

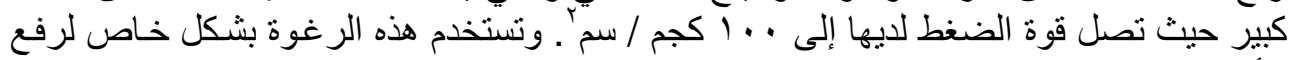

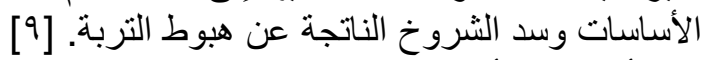

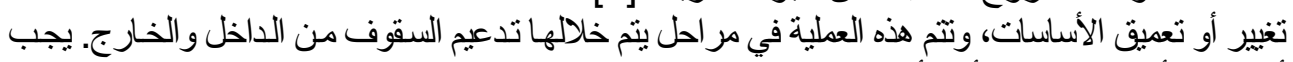

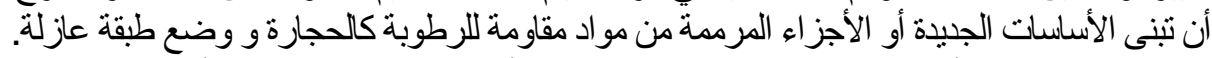

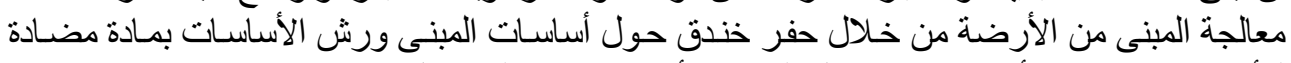

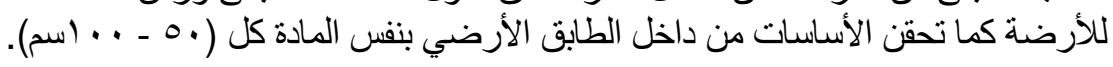

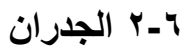

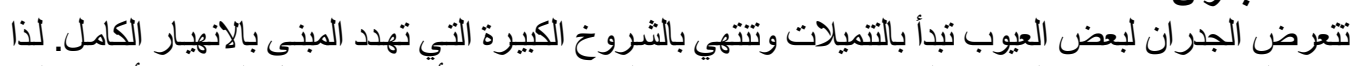

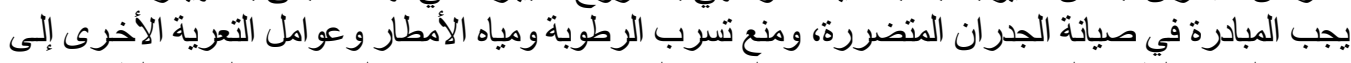

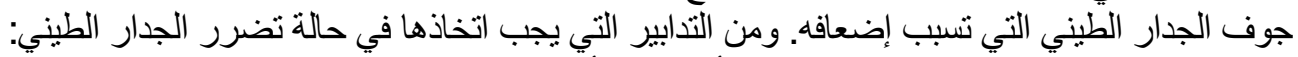

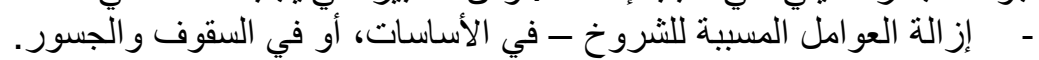

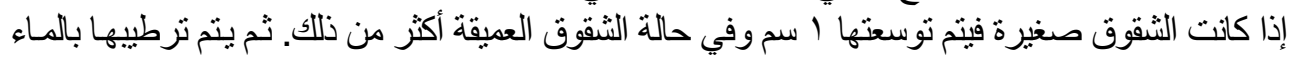

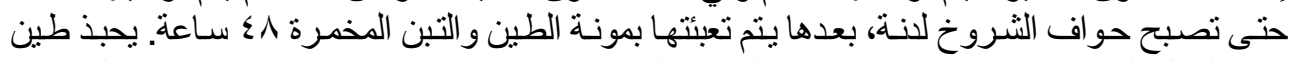

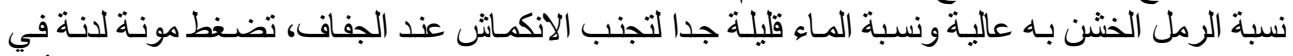

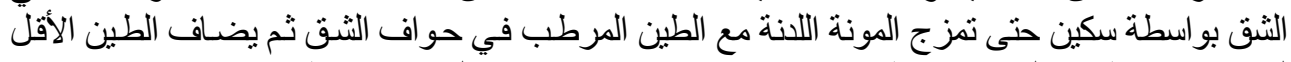

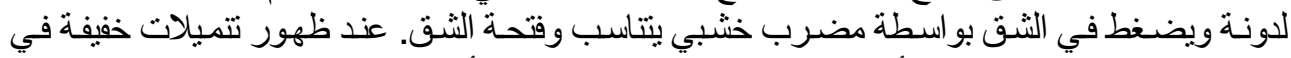

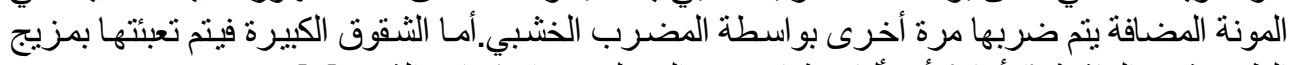

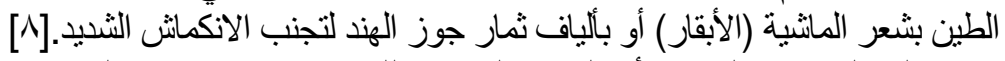

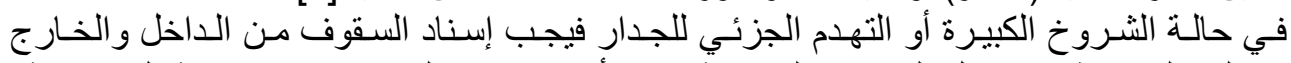

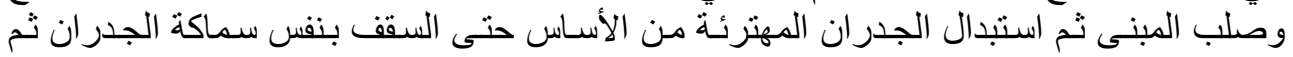

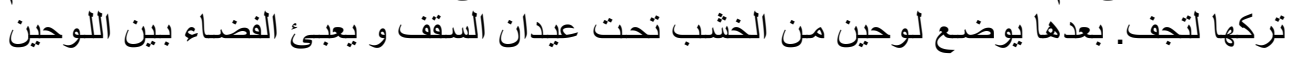


بخو ابير من الخشب ليتحمل الجدار الجديد أحمال السقف، بعدها يفك الإسناد. جدير بالذكر أن عملية الاستبدال هذه تنتاسب المباني الطينية قليلة الأدوار.

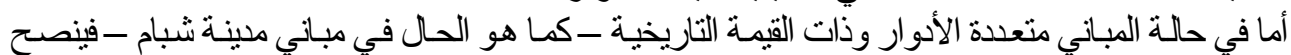

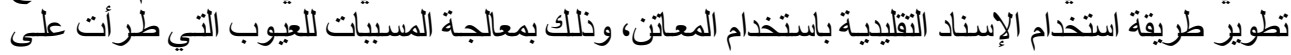

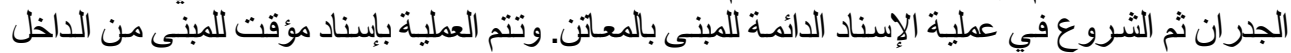

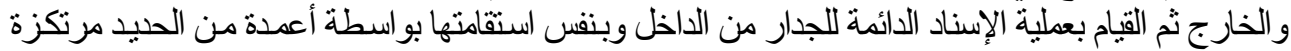

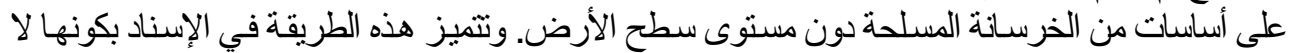

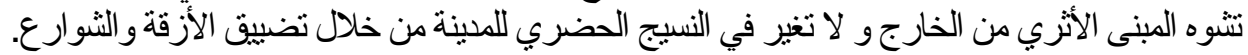

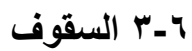

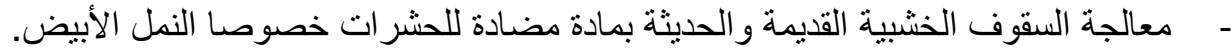

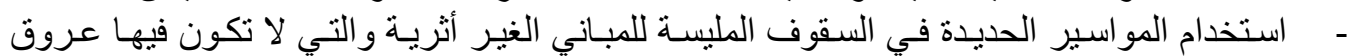

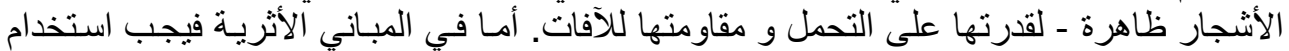

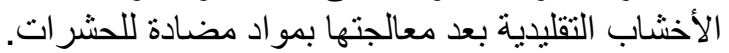
استخدام عازل للرطوبة في مناطق الرطوبة الربة. ـ - استخدام طبقة ميول في مناطق الرطوبة و البلل ـ الحمامات و المطابخ و السطوح.

\section{7- أك أعمال البياض واللياسة}

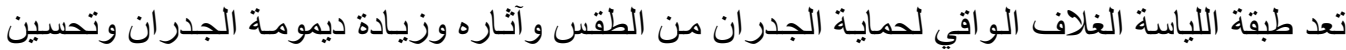

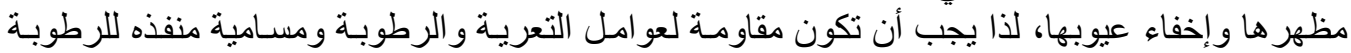

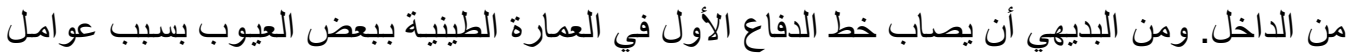

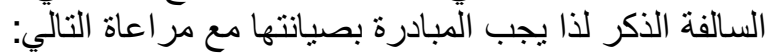

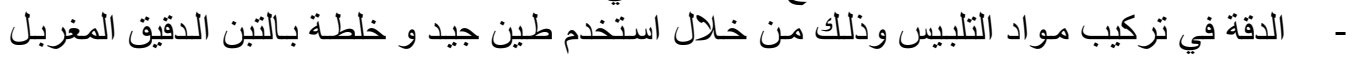

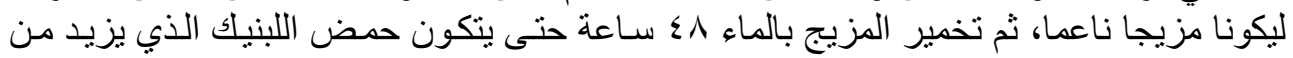

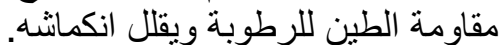

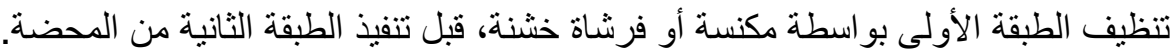

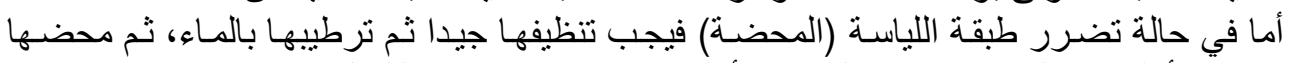

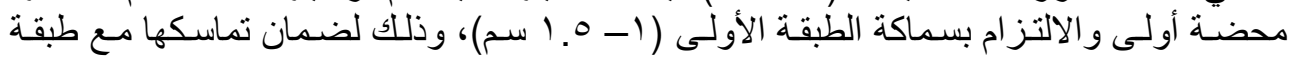

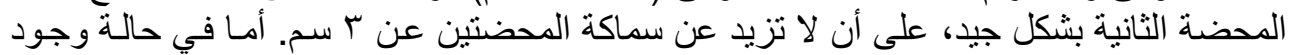

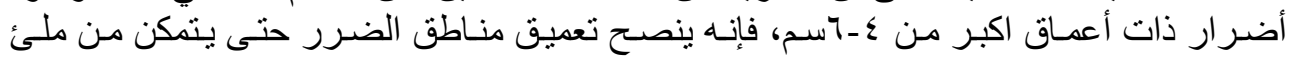

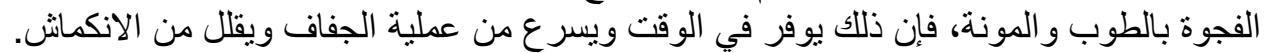

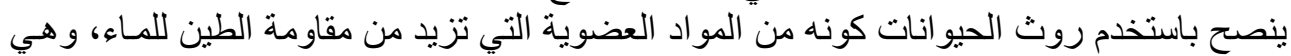

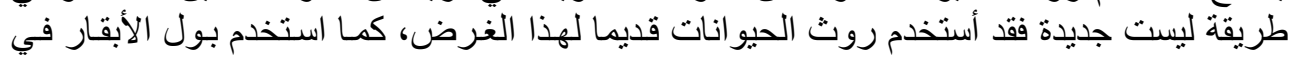
الهند كملاط نهائي للجدر ان الطينية. لسد التنميلات و ألثروخ الصغيرة الناتجة عن انكماش الطين ينصح استخدم مونة تحتوي مكوناتها

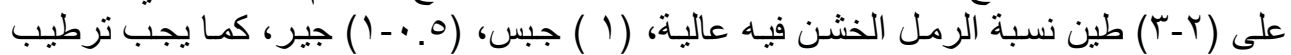

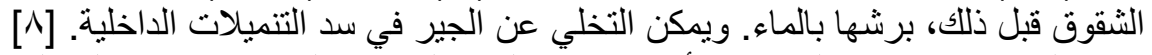

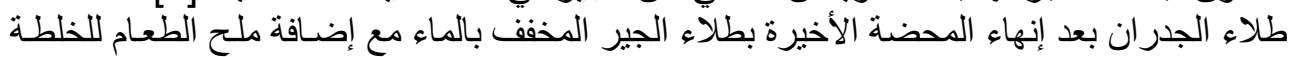

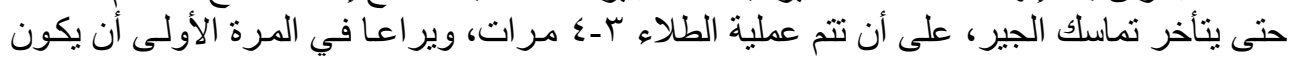

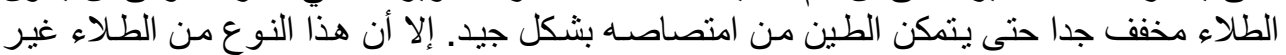

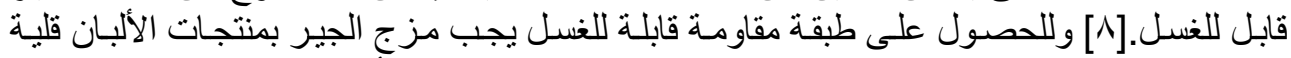

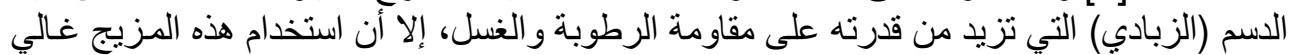

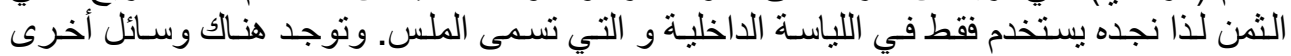




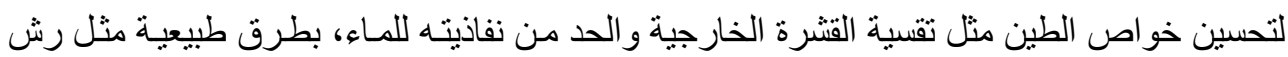

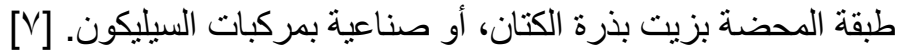

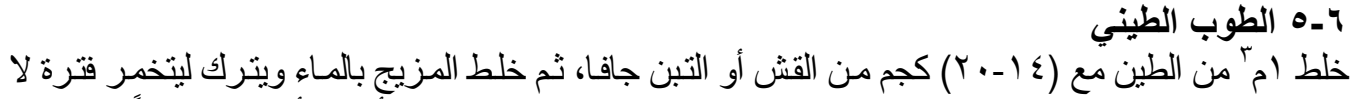
تقل عن (^^) ساعة. حيث ينتج عن التخمر حمض اللبنيك الذي يجعل الطوب أمنن وأقل امتصاصاً للماء.

\section{7- آ الإمدادات بالبنى الإرتكازية}

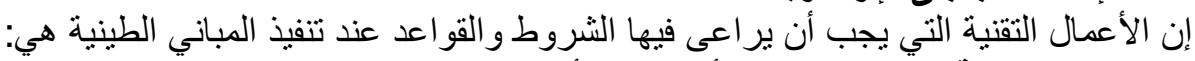

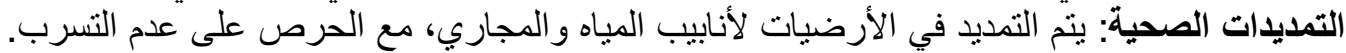

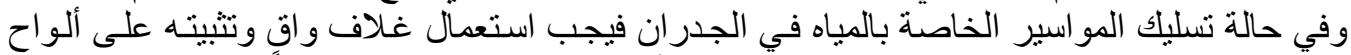

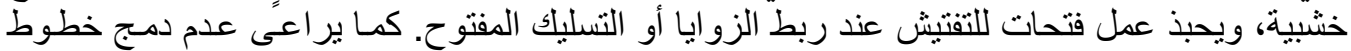

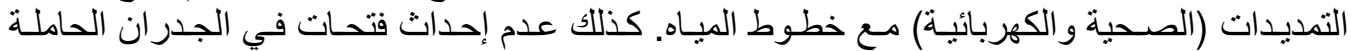

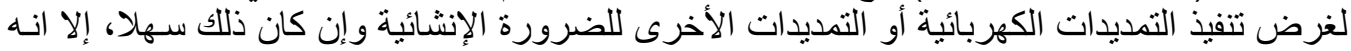
يتوجب عمل تصميمات مسبقة حتى يتم تتفيذ تلك الأعمال مباشرة أثناء البناء.

عزل الحمامـات: إن مصدر القلث بالنسبة للبيت الطينـي هو تسرب الميـاه إلى جدرانـهـ وتعتبر الحمامـات

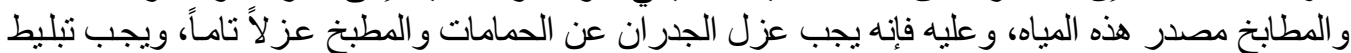

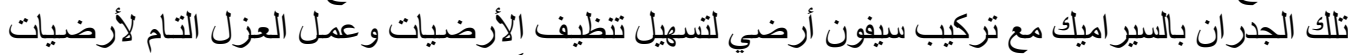

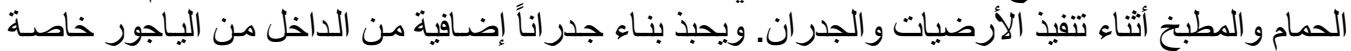
للحمامات، كما يجب تأمين تهوية جيدة لتلافي الاحنباس الهوائي داخل الحمامات ولات والمطابخ.

\section{أما بالنسبة للحمامات العلوية فيجب تنفيذها وفق الثروط التالية:}

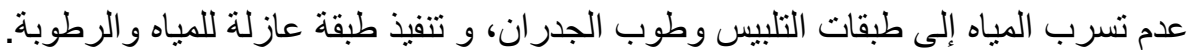

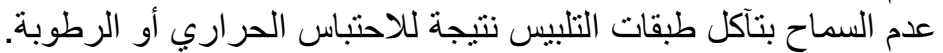

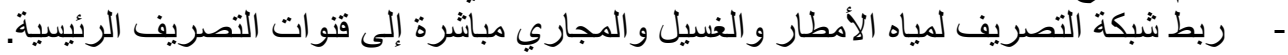
- مرورة الصيانة الدورية المستديمة.

V- التوصيات

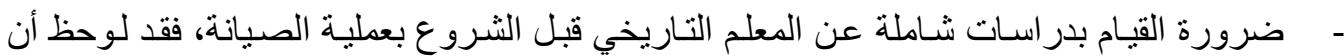

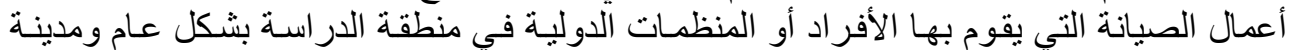

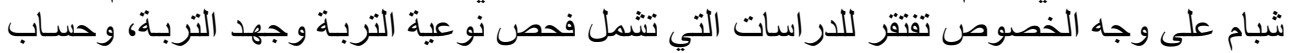

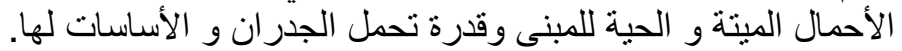

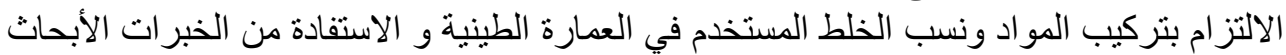

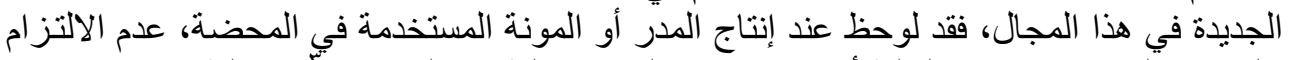

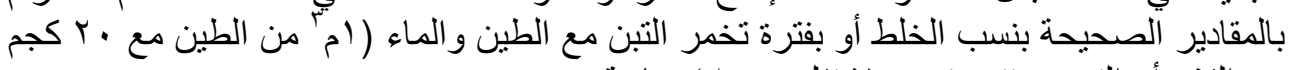

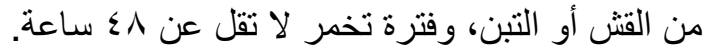
التحري الجيد لمسببات العيوب التي تصيب الأساسات و المبادرة التبات في إز التها قبل القيام بالإصلاحات.

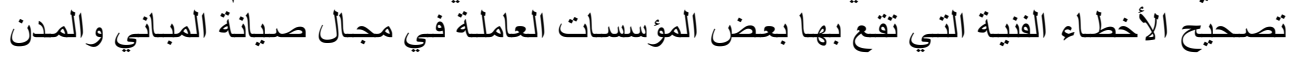

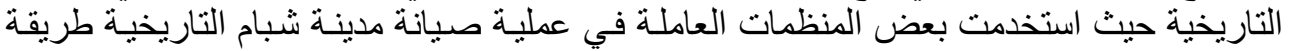

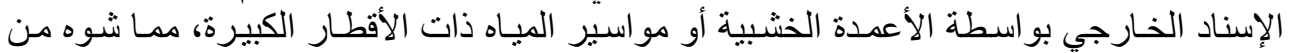

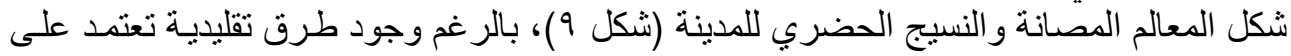

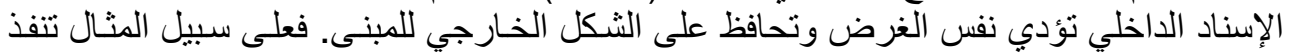

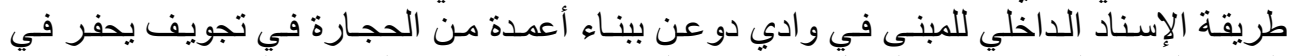
الجدار الطيني المتضرر من الداخل و بـه تسند السقوف. وتدي دوعى هذه الطريقة بالّنسيهيم. 
إن خبرة اليمنيين في مجـال البنـاء بـالطين تعد مـن أهم الخبرات نظراً للمخزون الثقافي والحضـاري

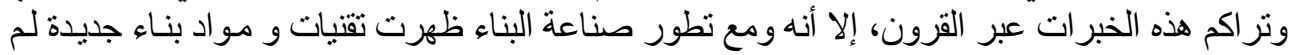

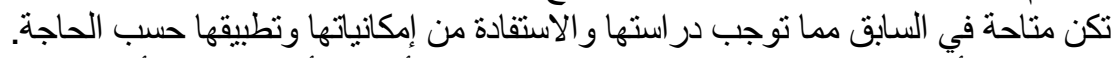

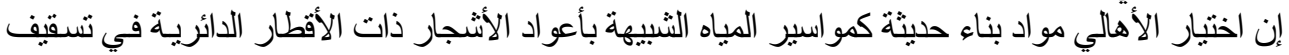

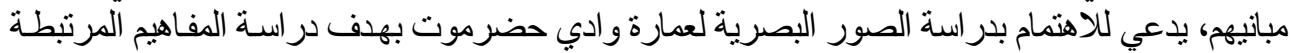

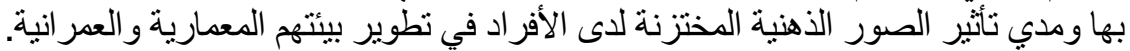

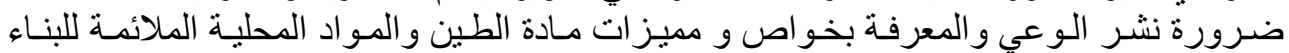

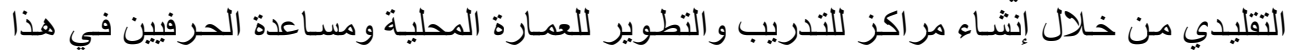

المجال، سيؤدي نقل هذه المهار ات و التقنيات المهددة بالانقر اض إلى إلى الأجيال القادمة.

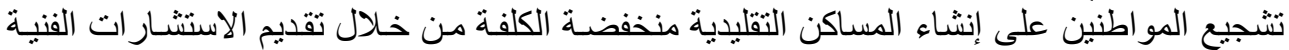

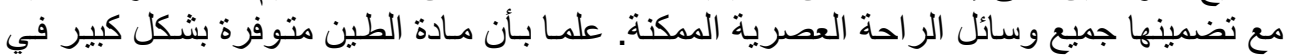

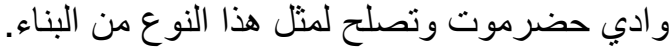
تطوير المو اد المستخدمة في صيانة المباني الطينية كونها مباني لاز الت الت تستخدم للأغر اض السناه السكنية و السكنية التجارية إضافة إلى أهميتها التراثية.

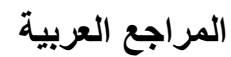

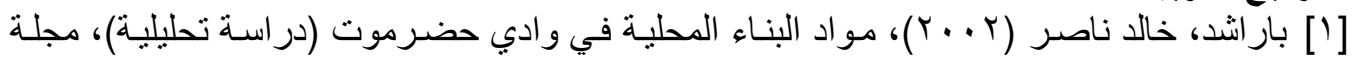

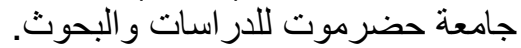

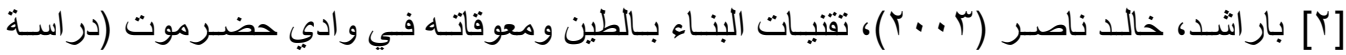

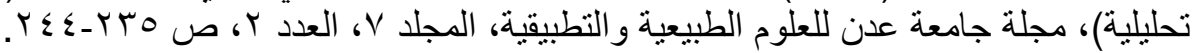

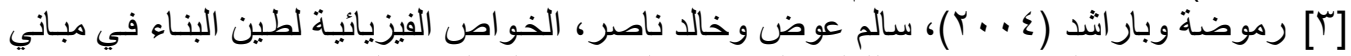

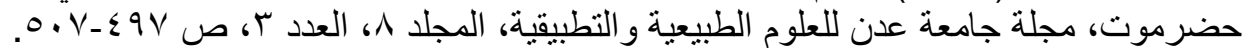

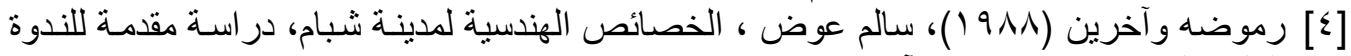

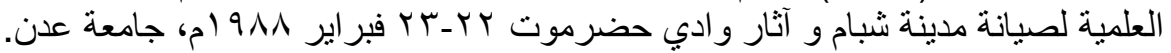

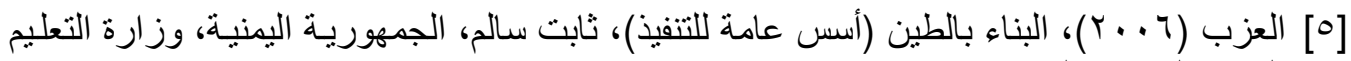

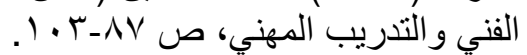

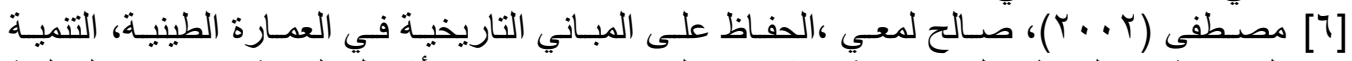

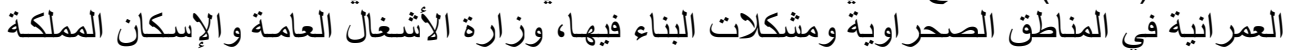

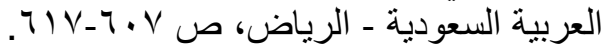

المراجع الأجنبية

[7] Houben and Guillaud (1994), Hugo, Hubert, Earth Construction, CRA Terre-EAG, 1994, pp. 331-345.

[8] Minke (1999), Gernot, Lehmbau-Handbuch, Oekobuch, Staufen bei Freiburg, pp 71-95.

[9] Schweizer Bau Dokumentation, 13/1/2005, Bodenverdichtung durch Uretek Deep Injektions, http://www.baudoc.ch/7/company/07/02/39/company_ 7.html. 